\title{
On the Transport of Buoyant Coastal Plumes
}

\author{
Felipe M. Pimenta,** A. D. Kirwan JR., AND Pablo HuQ \\ College of Earth, Ocean, and Environment, University of Delaware, Newark, Delaware
}

(Manuscript received 24 March 2010, in final form 23 July 2010)

\begin{abstract}
The role of discharge conditions and shelf geometry on the transport of coastal plumes is studied with a fully nonlinear, primitive equation hydrodynamic model. The physical setting is an estuarine channel with a small discharge Rossby number. By simulating different discharge magnitudes, buoyant plumes are shown to be succinctly described by a simple coastal front model. Three results emerge from the model analysis. First, the plume transport is given by $T=\gamma_{0}\left(g_{p}^{\prime} h^{2} / 2 f\right)$, where $\gamma_{0}$ is a parameter dependent on the ratio of the front and the plume widths, $g_{p}^{\prime}$ is the plume reduced gravity, $h$ is the plume maximum depth, and $f$ is the Coriolis parameter. Second, this model links the plume transport directly to upstream river conditions with $T=\gamma Q_{r}$, where $Q_{r}$ is the river outflow and $\gamma$ is a parameter that relates to entrainment, the geometry of the plume front and shelf slope, and the fraction of freshwater carried downshelf. Third, these equations reduce to analytic results previously established for special cases, providing useful formulas to estimate the plume transport from hydrographic and river discharge observations.
\end{abstract}

\section{Introduction}

Large-scale plumes are important features found on continental shelves formed by the inflow of freshwater to the ocean (Garvine 1995). In coastal regions, the buoyancy input represents a source of energy for the generation of shelf currents and a source of stratification that significantly modifies mixing processes (Simpson 1997; Hill 1998). These features tend to create biologically productive areas in shallow regions and ultimately serve as important gateways for the transfer of natural and toxic substances to the deep ocean (Henrichs et al. 2000; Moline et al. 2008).

Typically, plumes originate from distributed or point source outflows. The first case occurs when the buoyancy supply arises from numerous small rivers distributed along the coastline (Blanton and Atkinson 1983; Royer 1982). The second case, the focus of this study, occurs when the buoyant fluid enters the coastal ocean from an

\footnotetext{
* Current affiliation: National Institute for Space Research (INPE), Cachoeira Paulista, São Paulo, Brazil.

Corresponding author address: Felipe Pimenta, National Institute for Space Research (INPE), Rod. Presidente Dutra, km 40, Cachoeira Paulista, SP 12630-000, Brazil.

E-mail: felipe.pimenta@inpe.br
}

estuary or a bay mouth, and flows downshelf as a buoyancydriven coastal current (Fig. 1a).

Observations of bulges are rare, but depending on the discharge conditions, plumes resulting from point source outflows may form large bulges in front of the estuary. Their generation is described by the discharge Rossby number Ro $=v_{r} / f L_{r}$, where $v_{r}$ is the outflow velocity, $f$ is the Coriolis parameter, and $L_{r}$ is typically the channel breadth (Fong and Geyer 2002) or the radius of the estuary mouth corner (Avicola and Huq 2003b). For high-Ro outflows in idealized settings, the bulge shape is circular, and a significant fraction of the freshwater discharge is diverted to a growing bulge, which is in gradient-wind balance (Yankovsky and Chapman 1997; Horner-Devine et al. 2006). Low-discharge Ro outflows form small bulges, so a large part of the freshwater flows as a semi-geostrophic coastal current (Münchow and Garvine 1993b).

As they propagate downshelf, plumes can assume different forms. Surface-advected plumes expand across the ocean surface, displaying a large sectional area overriding ambient waters $\left(A_{n} / A_{s}<1\right)$ (Fig. 1b) (Lentz and Largier 2006). Bottom-advected or bottom-trapped $\left(A_{n} / A_{s}>1\right)$ plumes are those influenced by friction and thus dependent on the dynamics of the benthic boundary layer (Chapman and Lentz 1994). Intermediate types share the characteristics of both $\left(A_{n} / A_{s} \sim 1\right)$.

In their simplest representation, plumes are described as a two-layer Margules front, where buoyant waters of 


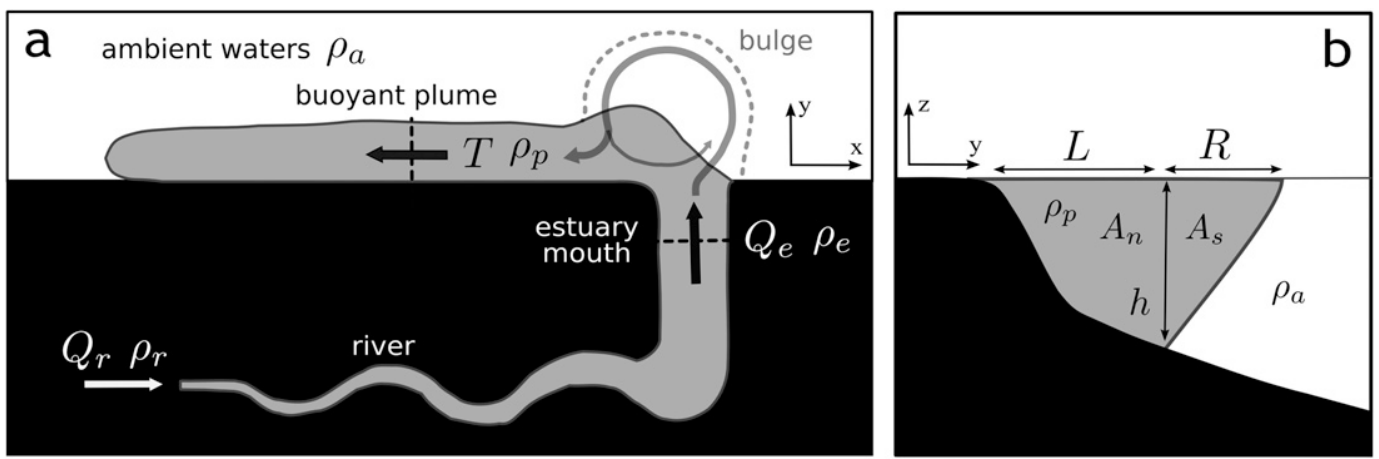

FIG. 1. (a) Cartoon of a buoyant plume, its bulge (shown as dashed line), estuary, and river basin. Here, $Q$ and $T$ are the transports. The river, estuary, plume, and ambient water densities are, respectively, $\rho_{r}, \rho_{e}, \rho_{p}$, and $\rho_{a}$. (b) Coastal current cross section with its geometry as proposed by Lentz and Largier (2006). Here, $h$ is the plume depth and $W_{p}=$ $L+R$ is the total width of the plume. In addition, $A_{n}$ is the plume nearshore area in contact with the bottom, $A_{s}$ is the region overriding the ambient waters, and $A_{p}=A_{n}+A_{s}$ is the plume total cross-sectional area.

density $\rho_{p}$ overlie a more dense, quiescent lower layer of density $\rho_{a}$ (Fig. 1b). For this configuration, the transport is given by $T=g_{p}^{\prime} h^{2} / 2 f$, where $h$ is the plume depth and $g_{p}^{\prime}=g\left(\rho_{a}-\rho_{p}\right) / \rho_{a}$ the reduced gravity. This frontal model has been extensively used in the development of theories and the scaling analysis of laboratory and numerical results (Garvine 1999; Lentz and Helfrich 2002; Fong and Geyer 2002). Other studies have considered the transport of stratified fronts in the coastal ocean. Yankovsky and Chapman (1997) showed that the transport of steep stratified fronts over a sloping shelf is similar to the Margules transport. Laboratory experiments for surface-advected plumes, on the other hand, yield a different relation $T=g_{p}^{\prime} h^{2} / 6 f$, which is valid for wide stratified plumes against a wall (Avicola and Huq 2003a). In the ocean, however, characteristics of buoyant plumes vary between the extremes of narrow and wide density fronts over mild and steep shelf slopes. Here, we develop a simple analytical model that permits the plume transport to be estimated for different shelf slopes and plume configurations.

A related issue is the linkage between the volume transport of coastal currents $T$ and the upstream discharge conditions $Q_{r}$ (Fig. 1a). Sometimes, the density anomaly and the volume transport of the river and the plume are assumed to be the same. This allows one to estimate important characteristics of the plume, such as its depth, $h=\sqrt{2 Q_{r} f / g_{r}^{\prime}}$, and its Rossby radius of deformation, $R_{d}=\left(2 Q_{r} g_{r}^{\prime}\right)^{1 / 4} / f^{3 / 4}$, where $g_{r}^{\prime}$ is the river inlet reduced gravity (Avicola and Huq 2002). In most situations however, the river outflow is largely augmented by the entrainment of ambient waters inside the estuary (Fig. 1a). Alternatively, the estuary mouth outflow $Q_{e}$ could be used to estimate plume properties over the shelf, as was done by Lentz and Largier (2006). However, $Q_{e}$ measurements are not as common as river-gauge observations, as they require long-term current-meter observations (e.g., Sanders and Garvine 2001) or indirect estimates from climatological data (Austin 2002).

Entrainment rates are also site-specific and dependent on mixing processes that are controlled by the estuary geometries and forcing mechanisms. In principle, however, the river discharge can be linked directly to the plume transport by the conservation of buoyancy, without recourse to the details of the dynamics of the estuaries.

Here, we unify previous analytic theories that relate upstream discharge conditions to the coastal plume transport by focusing on the effects of river discharge and bottom topography for low-Ro number discharges. We are particularly motivated by observations of plumes from the Delaware River (Wong and Münchow 1995; Sanders and Garvine 2001) and the Rio de la Plata (Guerrero et al. 1997; Möller et al. 2008). These are point source outflows characterized by very different discharge magnitudes and shelf slopes, but which share many characteristics, including the formation of small bulges. These plumes straddle the boundary between surface- and bottomadvected types, and also display conditions that are intermediate between the limiting cases of very narrow and wide density fronts.

We employ a primitive equation hydrodynamic model to simulate a broad range of discharges in an idealized physical setting. Subsequent analysis shows that the simulated plumes share characteristics that can be summarized by a simple model of a coastal front. This analytical model produces three useful results. First, we find that the plume transport can be reduced to $T=$ $\gamma_{0}\left(g_{p}^{\prime} h^{2} / 2 f\right)$, where $\gamma_{0}$ is a parameter dependent on the ratio of the front and the plume widths. Second, the model links the plume transport directly to upstream river conditions through $T=\gamma Q_{r}$, where $\gamma$ is a parameter 


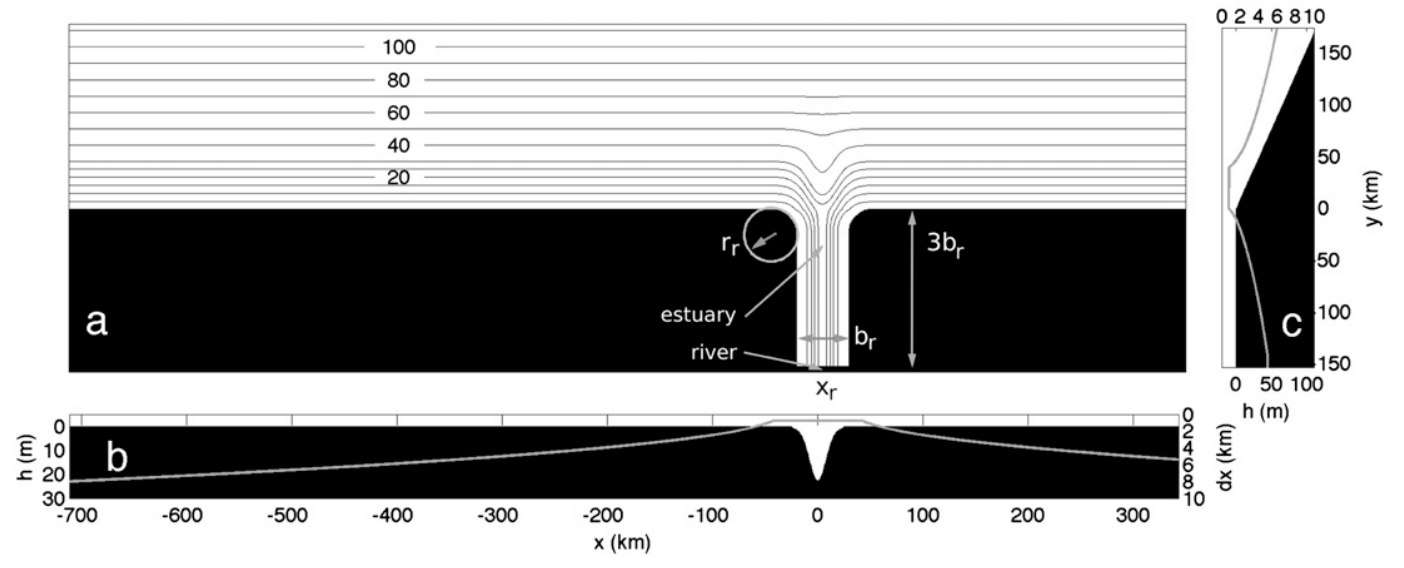

FIG. 2. (a) Model domain bathymetry with its (b) along- and (c) cross-shelf profiles. Isobaths are every $5 \mathrm{~m}$ between (5-30) $\mathrm{m}$, and every $10 \mathrm{~m}$ otherwise. The labels indicate the estuary breadth, $b_{r}$; radius of curvature, $r_{r}$; and position, $x_{r}$. The coastline $y_{c}$ coordinate is at $y=0$. The gray lines in (b) and (c) represent the grid spacing.

that relates to the entrainment of ambient waters, the geometry of the plume front, the shelf slope, and to the fraction of freshwater that is carried out downshelf. Third, the model recovers previously studied limit case solutions for narrow and wide fronts over mild and steep bottom slopes, thus linking all transport equations together.

The rest of this paper is divided into four sections. The next section describes the hydrodynamic model and the physical setting for the simulations. Results of the numerical experiments are given in the third section, where we explore the development of plumes as functions of different outflows. A theoretical model for a coastal front transport is outlined and evaluated in section 4 . The last section presents the summary and conclusions.

\section{Methods}

\section{a. Model description}

The model used here is the Princeton Ocean Model (POM; Blumberg and Mellor 1987), which is widely used in process-oriented and realistic coastal simulations. POM is a primitive-equation, finite-difference hydrostatic model that treats nonlinear time-dependent flows in three dimensions. The model uses curvilinear orthogonal coordinates for the horizontal grid and a sigma coordinate transformation $\sigma=(z-\eta) /(H+\eta)$ that scales the vertical coordinate $z$, with depth $H$, and the free surface $\eta$.

POM-dependent variables are the three components of velocity $u, v, w$; the surface elevation $\eta$; temperature $t$; salinity $s$; and two properties of the turbulence field: the turbulent macroscale and turbulent kinetic energy. The density, $\rho$, is computed from an equation of state. The model uses the continuity equation, the two horizontal momentum equations, and equations for the advectiondiffusion of heat and salt to compute those variables. POM incorporates the Mellor and Yamada (1982) level-2.5 turbulent closure scheme to parameterize vertical mixing, while the horizontal eddy viscosity uses the scheme of Smagorinsky (1963). In advecting the salt and temperature fields, the recursive scheme of Smolarkiewicz and Grabowski (1990) is used. POM's equations and numerical scheme are described in more detail by Mellor (2004).

For our application we use variable grid spacing. We apply a higher spatial resolution of $d x=d y=0.75 \mathrm{~km}$ for the estuary and for a nearshore band that is $\sim 40 \mathrm{~km}$ wide. Outside of these regions the grid spacing increases offshore and with larger distances from the estuary margins, reaching $d y=6 \mathrm{~km}$ at the offshore limit and $d x \sim 6$ and $d x \sim 8 \mathrm{~km}$ on its upshelf and downshelf boundaries (Fig. 2). For larger discharge simulations (i.e., $Q_{r}>$ $70000 \mathrm{~m}^{3} \mathrm{~s}^{-1}$ ), the estuary and nearshore grid spacing were coarser $(d x=d y=2 \mathrm{~km})$ to increase the computational efficiency of larger domains. In the vertical, 21 sigma layers were employed. Domains varied in size, but the largest case was approximately $1500 \mathrm{~km} \times 500 \mathrm{~km}$ and had $425 \times 160$ horizontal grid cells.

\section{b. Boundary and initial conditions}

Boundary conditions imposed at the free surface are zero wind stress and zero flux of salt and heat. At the bottom, heat and salt fluxes are absent. The bottom stress is computed using the velocities at the bottom grid cell and a quadratic drag law. The model is initialized with ambient salinity at $s_{a}=34$ and temperature $t_{a}=15^{\circ} \mathrm{C}$. The river discharge is specified by constant 
velocities at the channel head with constant salinity $s_{r}=$ 20 and temperature $t_{r}=15^{\circ} \mathrm{C}$. The Coriolis parameter is set to $f=-8.75 \times 10^{-5} \mathrm{~s}^{-1}$, which is appropriate for a latitude of $37^{\circ} \mathrm{S}$.

Cyclic (periodic) boundary conditions were imposed on the upshelf and downshelf boundaries as in Chao (1987), Klinck (1996), and Gan and Allen (2002). Offshore the Flather radiation condition (Flather 1976) is applied for the boundary-normal depth-averaged velocity $V$ and a nongradient condition is applied for elevation $\eta$ and the depth-averaged tangential velocity $U$. The Orlanski (1976) scheme is applied for the offshore boundary velocities $u$ and $v$, while the thermohaline fields are brought to the domain's reference values by applying the relaxation scheme proposed by Martinsen and Engedahl (1987).

\section{c. Shelf and estuarine setting}

Our focus is on plumes with small bulges and where the freshwater transport flows dominantly downshelf. As we vary the river discharge over two orders of magnitude (i.e., $1000 \leq Q_{r} \leq 100000 \mathrm{~m}^{3} \mathrm{~s}^{-1}$ ), the inlet width is computed as function of the river outflow $Q_{r}$, the river inlet cross-sectional area $A_{r}$, and the discharge Rossby number Ro (Fong and Geyer 2002):

$$
b_{r}=\frac{Q_{r}}{f \operatorname{Ro} A_{r}},
$$

where we have set Ro $\sim 0.01$ to suppress the formation of large bulges. Although it is common to specify the discharge by a rectangular inlet positioned at the coastal wall, this method is not applied here, as it can cause the modeled plume to intrude upshelf. This can be avoided by specifying more realistic bathymetry, density, and flow fields at the estuary mouth (Garvine 2001). To generate these conditions, we incorporate a long channel and implement the river outflow at its upstream end, allowing the development of circulation and entrainment within the estuary. The river and estuary have a total length of $3 b_{r}$ and a $90^{\circ}$ exit angle with the coastline, as it represents a more generic angle configuration. Its cross-sectional profile incorporates vanishing depth on its sidewalls:

$$
h_{\text {chan }}(x, y)=h_{r}^{*} e^{-x^{2} / 2 \sigma_{r}^{2}},
$$

where $\sigma_{r}=b_{r} / 6$ and $h_{r}^{*}(y)=h_{r} / 2\left\{1-\tanh \left[\left(y-y_{c}+a\right) / c\right]\right\}$. The coastal wall position is $y_{c}$ and the other parameters are set as $a=50 \mathrm{~km}$ and $c=a / 2$. Note that both rivers and estuaries have similar shapes and thus are simply represented by a channel of constant depth and width. Near the estuary mouth the channel has "round"
TABLE 1. Model river channel configuration as a function of the outflow magnitude, $Q_{r}\left(\mathrm{~m}^{3} \mathrm{~s}^{-1}\right)$. Here, $b_{r}$ is the breadth $(\mathrm{km}), h_{r}$ the maximum depth (m), $A_{r}$ the channel cross-sectional area $\left(\mathrm{km}^{2}\right), g_{r}^{\prime}$ the reduced gravity $\left(\mathrm{m} \mathrm{s}^{-2}\right)$, and $v_{r}$ the river outflow velocity, computed as $v_{r}=Q_{r} / A_{r}\left(\mathrm{~m} \mathrm{~s}^{-1}\right)$.

\begin{tabular}{rcrccc}
\hline \hline \multicolumn{1}{c}{$Q_{r}$} & $b_{r}$ & \multicolumn{1}{c}{$h_{r}$} & $A_{r}$ & $v_{r}$ & $g_{r}^{\prime}$ \\
\hline 1000 & 17.88 & 8.08 & 0.06 & 0.02 & 0.1028 \\
2000 & 22.52 & 9.59 & 0.10 & 0.02 & 0.1028 \\
5000 & 30.57 & 13.44 & 0.19 & 0.03 & 0.1028 \\
7500 & 34.99 & 15.55 & 0.24 & 0.03 & 0.1028 \\
10000 & 38.51 & 17.24 & 0.30 & 0.03 & 0.1028 \\
15000 & 44.09 & 19.91 & 0.39 & 0.04 & 0.1028 \\
20000 & 48.52 & 22.03 & 0.47 & 0.04 & 0.1028 \\
25000 & 52.27 & 23.83 & 0.55 & 0.05 & 0.1028 \\
30000 & 55.54 & 25.39 & 0.62 & 0.05 & 0.1028 \\
40000 & 61.14 & 28.07 & 0.75 & 0.05 & 0.1028 \\
50000 & 65.86 & 30.33 & 0.87 & 0.06 & 0.1028 \\
60000 & 69.98 & 32.31 & 0.98 & 0.06 & 0.1028 \\
70000 & 73.67 & 34.07 & 1.09 & 0.06 & 0.1028 \\
80000 & 77.03 & 35.68 & 1.19 & 0.07 & 0.1028 \\
90000 & 80.11 & 37.15 & 1.28 & 0.07 & 0.1028 \\
100000 & 82.97 & 38.52 & 1.38 & 0.07 & 0.1028 \\
\hline
\end{tabular}

estuary corners of radius $r_{r}=b_{r} / 2$ (see Avicola and Huq 2003b) and it decays in depth offshore, merging to the shelf bathymetry.

The shelf is specified by $h_{\text {shelf }}=h_{c}+\alpha\left(y-y_{c}\right)$, with $h_{c}=0.5 \mathrm{~m}$ as the coastal wall depth and $\alpha$ as the shelf slope; for $y<y_{c}$, we set $h_{\text {shelf }}=h_{c}$. For milder shelf slope simulations we choose $\alpha=0.65 \times 10^{-3}$, which is of comparable magnitude to the midshelf region of the Rio de la Plata plume (Fig. 5c in Piola et al. 2008). For steeper shelf simulations, we choose a slope that is 3 times larger $\left(\alpha \sim 2 \times 10^{-3}\right)$ and comparable to the Delaware plume inner-shelf slope (Fig. 9c in Wong and Münchow 1995). In this paper we refer to $\alpha=0.65 \times 10^{-3}$ as mild and $\alpha=$ $2 \times 10^{-3}$ as steep. Note, however, these are in the lowerto midrange of bottom slopes considered in previous works [e.g., $\alpha=(1-3) \times 10^{-3}$ in Yankovsky and Chapman (1997); $\alpha=\left(0-10^{-2}\right)$ in Garvine (1999)].

The model bathymetry is specified by

$$
H(x, y)=h_{\text {shelf }}(y)+h_{\text {chan }}(x, y),
$$

and the domain's isobaths and its along-and across-shelf sections are shown in Fig. 2. The channel breadth $b_{r}$ is computed from Eq. (1) with the cross-sectional area $A_{\text {chan }}=\left(\sqrt{2 \pi} h_{r} / 6+h_{c}\right) b_{r} \sim h_{\mathrm{eq}} b_{r}$ from (2). To generate channels of similar aspect ratio, we employ $h_{\mathrm{eq}}=\delta b_{r}$, with $\delta=2 \times 10^{-4}$ so that $A_{r}=A_{\text {chan }} \sim \delta b_{r}^{2}$ and we can express (1) as

$$
b_{r}=\left(\frac{Q_{r}}{\delta f \mathrm{Ro}}\right)^{1 / 3} .
$$



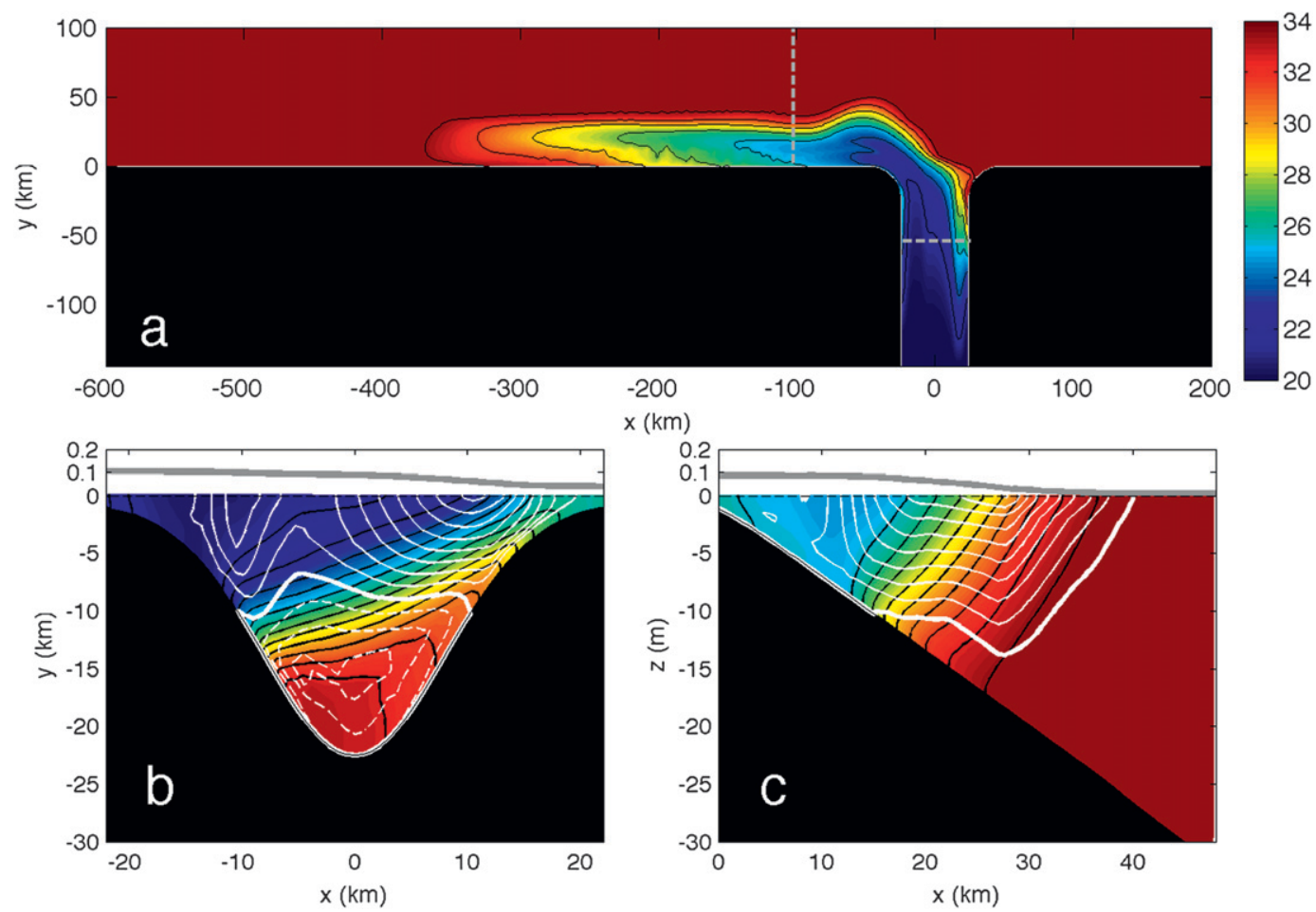

FIG. 3. Plume horizontal and vertical sections for the mild slope shelf and $Q_{r}=20000 \mathrm{~m}^{3} \mathrm{~s}^{-1}$ for (a) the surface salinity, (b) an estuary cross section, and (c) a coastal current section. Salinity is depicted by the color scale and black contours. Velocity is depicted by white contours of $\delta_{u}=0.05 \mathrm{~m} \mathrm{~s}^{-1}$ increments. Velocities into (out of) the page are shown by solid (dashed) lines. The gray line depicts the sea surface $\eta$, which is exaggerated in this plot for clarity.

Equation (4) specifies the channel breadth as a function of river outflow, aspect ratio, and the discharge Rossby number. With $b_{r}$, one can compute the channel depth $h_{r}$ and hence $h_{\text {chan }}(x, y)$. Land grid cells are masked for depths $\leq 0.5 \mathrm{~m}$. Note that in (4) we use the river source and not the estuary mouth conditions for simplification. In reality entrainment will increase the outflow, which can be twice as large as that prescribed at the estuary head. The change in the discharge Ro number, however, is small and still guarantees the formation of small bulges (Ro remains $<0.05$ ). In Table 1 the estuarine parameters are listed for the different discharge cases.

\section{Numerical model results}

Here, the results of the numerical simulations for plumes over mild and steep shelf slopes are described. We begin with the basic description of the estuary and the plume circulation, and follow with an analysis of the effects of the outflow magnitude on the coastal plumes geometry and growth.

\section{a. Estuarine and plume circulation}

As the freshwater is supplied to the shelf, the coastal plume propagates downstream moving to large distances from the estuary mouth. A plume's typical surface salinity field is shown in Figs. 3a and 4a for the cases of mild and steep shelf slopes, respectively. In both situations no upshelf intrusion occurs, but a small bulge is formed downstream from the estuary. For the steep shelf slope the bulge offshore extension is larger and the coastal current narrower than for the mild shelf slope. Both plumes form a nose at the downstream edge.

Figures $3 \mathrm{~b}$ and $4 \mathrm{~b}$ show the salinity and velocity structure across the estuary mouth. Low-salinity waters occupy an upper-layer outflow, while a return flow is associated with saltier deeper waters. The estuarine outflow is augmented by entrainment from the lower layer, so that the volume transport is nearly twice the value prescribed at the estuary head. We show later that the majority of the entrainment occurs before the exit of estuarine waters to the open ocean, which is upstream of the bay mouth.

Transverse variability in the salinity field develops as the channel breadth is larger than the internal Rossby radii of deformation. The estuarine velocity field is horizontally sheared with larger velocities on the righthand side of the channel, for a viewer looking toward the ocean (Figs. 3b and 4b). The circulation observed is consistent with the frictionally adjusted flow limit of 

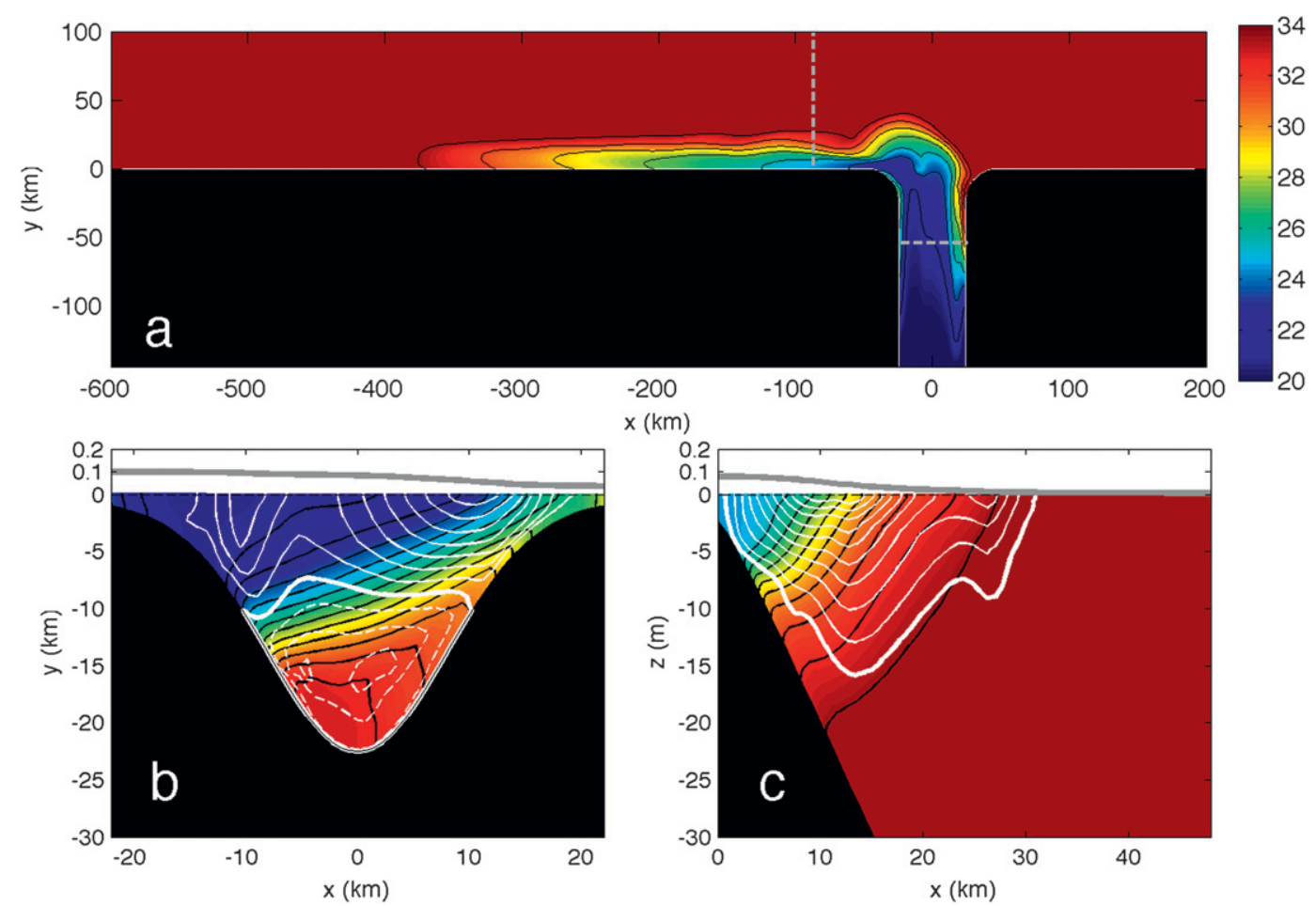

FIG. 4. As in Fig. 3, but for a steep shelf slope.

dynamically wide estuaries (Valle-Levinson 2008). Further downstream and over the shelf the coastal plume evolves as a stratified front with its salinity increasing offshore (Figs. 3c and 4c). The frontal boundary or maximum plume depth is around $h=17 \mathrm{~m}$. Both fronts possess similar widths and slopes. The size of the region occupied by buoyant waters, however, is larger for the mild slope case, where the front is situated farther away from the coast.

The along-shelf flow of a buoyant plume is nearly in geostrophic balance (Münchow and Garvine 1993a; Fong and Geyer 2002). Because of the plume buoyancy anomaly, the sea surface $\eta$ is highest near the coast and decays offshore as the density increases. Through geostrophy, this generates downshelf velocities at the surface. The core of the coastal current is positioned offshore, in the region of maximum sea surface slope (Figs. 3c and 4c). As the pressure gradient established by the density field increases with depth, it opposes the sea surface pressure gradient. As a result, the surface jet slows down so that weaker velocities occur near the bottom and along the plume's offshore edge. Near the bottom, the flow is nearly quiescent where the foot of the plume becomes trapped at the depth $h$ (Chapman and Lentz 1994). The foot of the plume is at $y=h / \alpha=L$. For the cases shown, the mild shelf plume is classified as intermediate to bottom advected, and the plume for the steep shelf slope as intermediate to surface advected. The simulations show the development of the coastal current and trapping of the plume's fronts to the bottom.

\section{b. The effects of outflow magnitude on coastal plumes}

We studied the effects of the magnitude of river discharge on the structure and strength of coastal plumes by performing 16 simulations on both shelf slopes under constant buoyancy anomaly, while varying the outflows over the range of $1000 \leq Q_{r} \leq 100000 \mathrm{~m}^{3} \mathrm{~s}^{-1}$ (Table 1). The surface plume evolution can be followed in the top panels of Figs. 5 and 6, which show the plume boundary (defined as the $s \sim 33.5$ isohaline) as a function of time. Buoyant plumes have different sizes but similar shapes, forming small bulges, weak upshelf intrusions, and welldeveloped coastal currents. We find that $50 \%$ or more of the freshwater flux is delivered downshelf for steep shelf slope simulations. For mild shelf slopes the freshwater delivery is $\geq 70 \%$. The plume downshelf position $L_{x}$ and maximum cross-shelf extent $L_{y}$ are further summarized in Fig. 7. Here, the time 0 in all of the graphs is defined as the time that the nose of the plume crosses the estuary mouth at $y=0$. These graphs reveal plumes that extend from $L_{x} \sim 100$ to $600 \mathrm{~km}$ downshelf and from $L_{y} \sim 20$ to $80 \mathrm{~km}$ offshore after 35 days. Their growth was directly related to river discharge, but smaller downshelf penetration and wider offshore expansions occurred for 

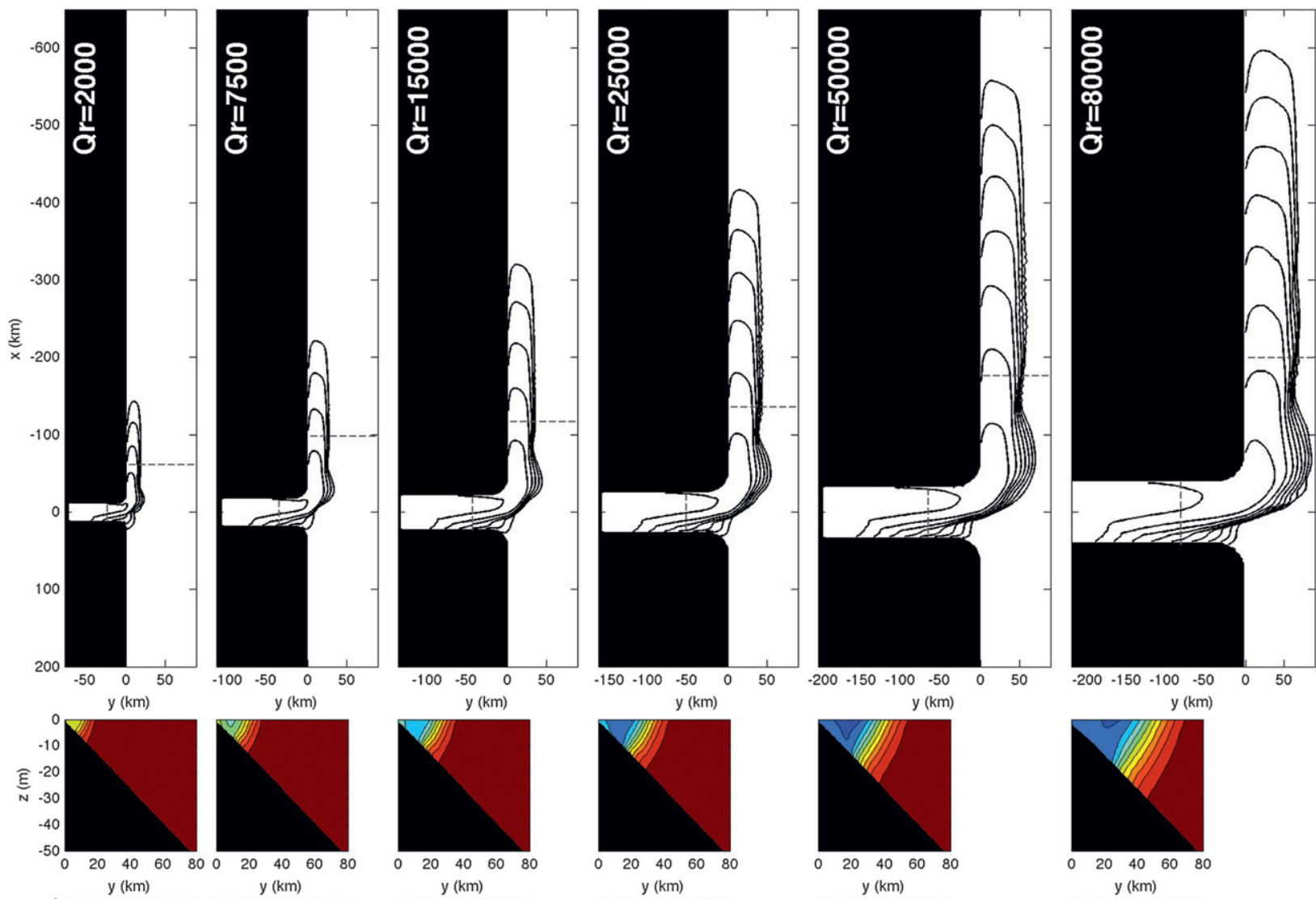

$y(\mathrm{~km})$
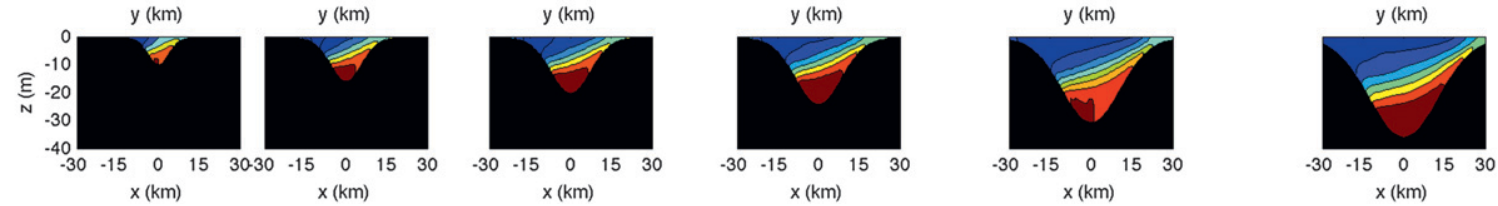

FIG. 5. (top) Coastal plume evolution patterns in time for different river discharges and a mild shelf slope. Each contour depicts the plume limit $(s \sim 33.5)$ in steps of 5 days. (middle) Coastal plume salinity cross sections and (bottom) estuary sections are shown. Crossshelf sections are sampled between (10-20) $R_{d}$ downshelf of the estuary mouth. Estuary sections are sampled a distance $r_{r}$ from the mouth. The estuary breadth and length are specified as function of river discharge; see text for details. Salinity sections have unit contour intervals.

mild shelf slopes when compared to the steep shelf cases. More importantly, these curves collapse to the black lines in Fig. 7 when the distances are scaled by the inlet Rossby radius of deformation, $R_{d}=\left(2 Q_{r} g_{r}^{\prime}\right)^{1 / 4} / f^{3 / 4}$. The plumes expand in a matter of a few days to near 6 or 7 Rossby radii offshore, while a smaller rate of growth is observed after 10 days. The alongshelf extent is between $(50-60) R_{d}$, which is approximately similar to Avicola and Huq's (2003a) laboratory experiments.

Estuary and coastal cross sections revealed similar salinity structures despite the differing river discharge and estuary breadths (Figs. 5 and 6). This is further illustrated for the coastal front by comparing the crossshelf surface salinity distribution for the mild and the steep shelf slope simulations in Fig. 8. The salinity profiles collapse to the curves of Figs. $8 \mathrm{c}$ and $8 \mathrm{~d}$ when the $y$ cross-shelf coordinate is scaled by the plume total width $y^{*}=y / W_{p}$ and the salinity $s$ as $s^{*}=\left(s-s_{p}\right) /\left(s-s_{a}\right)$, where $s_{p}$ and $s_{a}$ are the plume and the ambient waters salinity.

\section{A simple model for a coastal front}

\section{a. Transport equation}

The above results show that a plume density front is well represented by a linear transition from fresher waters of density $\rho_{p}$ to ambient shelf waters of density $\rho_{a}$. Such a simple configuration can be specified by four parameters: $h, \alpha, W$, and $\beta$, which represent the plume maximum depth, the shelf slope, the frontal zone width, and the slope of the density field. The density fields for two possible situations are shown in Fig. 9. The geometry ignores variations in the plume surface height, 

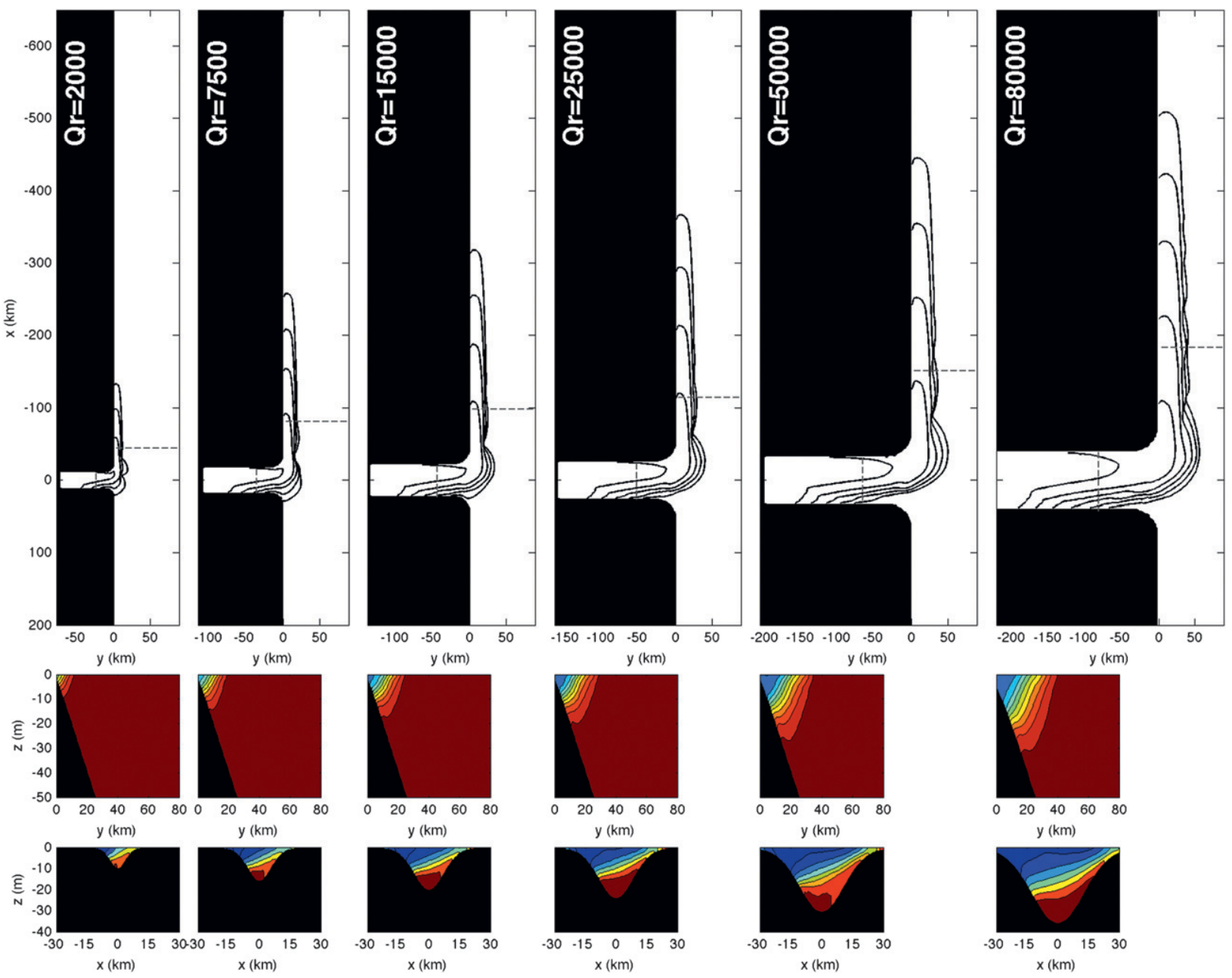

FIG. 6. As in Fig. 5, but for a steep shelf slope.

and the front limits are described by $L_{s}=L+R$ and $L_{b}=L+R-W$ at the surface $(z=0)$ and $L$ and $L_{i}=$ $L(L+R-W) /(L+R)$ near the bottom. The shelf and isopycnal slopes are given, respectively, by $\alpha=h / L$ and $\beta=h / R$, and the density front is specified as

$$
\rho(y, z)=\rho_{a}-\Delta \rho_{p}\left(1-\frac{y-L-R+W}{W}+\frac{R}{W} \frac{z}{h}\right),
$$

where the plume density difference from ambient waters is $\Delta \rho_{p}=\rho_{a}-\rho_{p}$. Assuming the along-shelf flow is geostrophic and hydrostatic, we can obtain an expression for the velocity field from the thermal wind relation:

$$
u(y, z)=u_{o}+\frac{g}{\rho_{a} f} \int_{z}^{o} \frac{\partial \rho}{\partial y} d z=u_{o}+\frac{g_{p}^{\prime}}{f} \frac{z}{W},
$$

where $g_{p}^{\prime}=g \Delta \rho_{p} / \rho_{a}$ is the plume reduced gravity, $u_{o}(y)$ is a reference surface velocity, and the integral represents the along-shelf velocity shear with depth. We can find $u_{o}$ and thus a final expression for the velocity field if we also assume that the velocity vanishes at the bottom $z_{b}=-h(y / L)$, and also along the plume offshore edge $z_{s}=h(y-L-R) / R$ [i.e., $u\left(y, z_{b}\right)=u\left(y, z_{s}\right)=0$ ]. With these conditions we find

$$
u_{b}(y, z)=\frac{g_{p}^{\prime} h}{f W}\left(\frac{y}{L}+\frac{z}{h}\right),
$$

and

$$
u_{s}(y, z)=\frac{g_{p}^{\prime} h}{f W}\left(\frac{R+L-y}{R}+\frac{z}{h}\right)
$$

where $u_{b}$ is valid over the regions $A_{b 1}, A_{b 2}$, and $A_{b}$; and $u_{s}$ over the regions $A_{s}, A_{\mathrm{s} 1}$, and $A_{\mathrm{s} 2}$ shown in Figs. 9b 

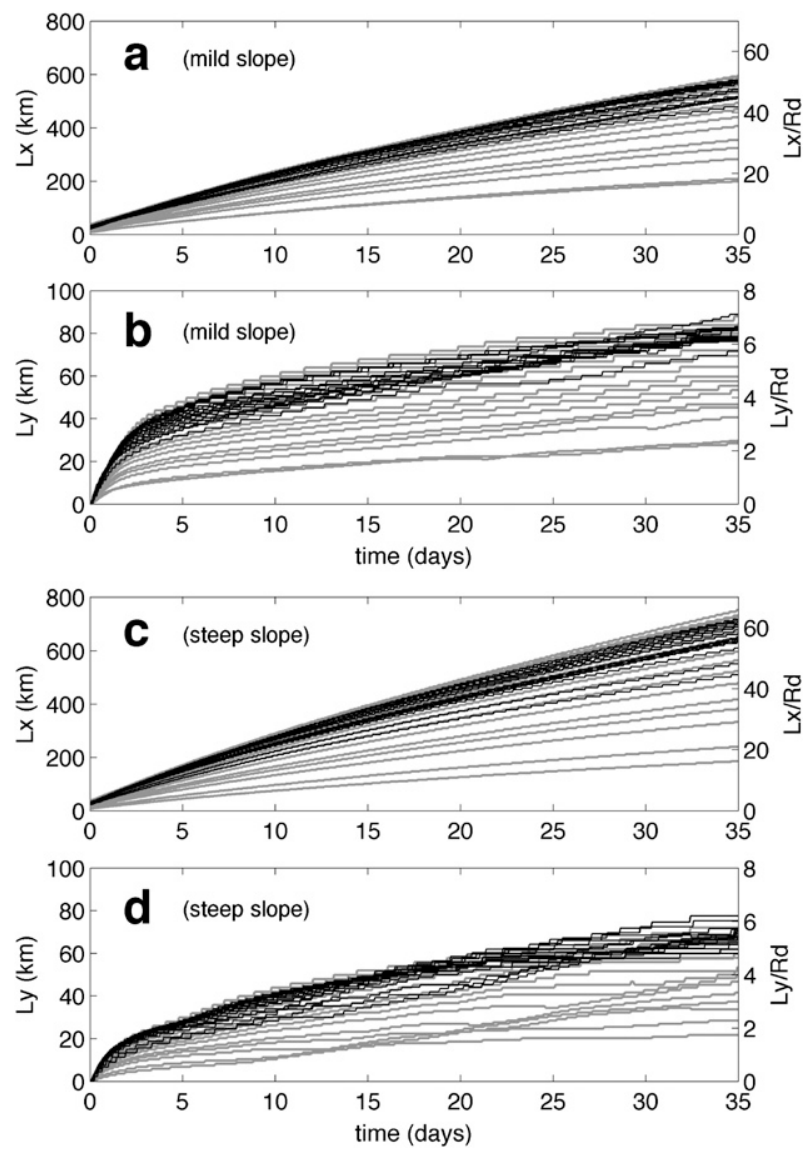

FIG. 7. Downshelf evolution of the plumes as a function of time for (a) mild and (c) steep shelf slopes. The plume downshelf position $L_{x}(\mathrm{~km})$, is measured from the nose distance of the estuary mouth, $x_{r}$. The across-shelf growth $L_{y}(\mathrm{~km})$ of the plume as a function of time for (b) mild and (d) steep slopes. Gray lines correspond to the distance measured in $\mathrm{km}$. Black lines correspond to distances scaled by the Rossby radius of deformation $\left(L_{x} / R_{d}, L_{y} / R_{d}\right)$.

and $9 \mathrm{~d}$. For the region inshore of the plume fronts, there is no vertical shear of the along-shelf flow above $z_{i}=h(y-L-R+W) / R$, as $\partial \rho / \partial y=0$ there. The velocity field for this region can be obtained from $u_{s}$ and $u_{b}$, observing that there will be two cases, shown in Figs. 9b and 9d. For the wider front limit, $R \leq W \leq L+R$, the velocity is specified by requiring $u_{i}^{b}(y)=u_{b}\left(y, z_{i}\right)$ :

$$
u_{i}^{b}(y)=\frac{g_{p}^{\prime} h}{f W}\left(\frac{y}{L}+\frac{y-L+W-R}{R}\right),
$$

where $u_{i}^{b}$ is valid for $A_{i}$ depicted in Fig. 9b. For the case of a narrow front, $0 \leq W \leq R$, the above expression is valid over the region $A_{i 1}$ shown in Fig. 9d. The region $A_{i 2}$ has its velocity field specified by $u_{i}^{s}(y)=u_{s}\left(y, z_{i}\right)$ :

$$
u_{i}^{s}=\frac{g_{p}^{\prime} h}{f R} .
$$

Inshore of $L_{i}$ and offshore of $z_{s}$, the alongshelf flow is quiescent $(u \sim 0)$.

Equations (7)-(10) define the along-shelf velocity field within these plumes, which is shown by the black contours in Figs. 9b and 9d. These velocity fields depict an alongshore jet centered around $y \sim L$. These expressions can be integrated for the cases shown in Fig. 9. For the wider front,

$$
\begin{aligned}
T_{i} & =\int_{L_{i}}^{L_{b}} \int_{z_{i}}^{0} u_{i}^{b} d z d y ; \\
T_{b} & =\int_{L_{i}}^{L_{b}} \int_{z_{b}}^{z_{i}} u_{b} d z d y+\int_{L_{b}}^{L} \int_{z_{b}}^{0} u_{b} d z d y ; \\
T_{s} & =\int_{L}^{L_{s}} \int_{z_{s}}^{0} u_{s} d z d y .
\end{aligned}
$$

Similarly for the narrower front configuration, these become

$$
\begin{aligned}
T_{i} & =\int_{L_{i}}^{L} \int_{z_{i}}^{0} u_{i}^{b} d z d y+\int_{L}^{L_{b}} \int_{z_{i}}^{0} u_{i}^{s} d z d y ; \\
T_{b} & =\int_{L_{i}}^{L} \int_{z_{b}}^{z_{i}} u_{b} d z d y ; \\
T_{s} & =\int_{L}^{L_{b}} \int_{z_{s}}^{z_{i}} u_{s} d z d y+\int_{L_{b}}^{L_{s}} \int_{z_{s}}^{0} u_{s} d z d y .
\end{aligned}
$$

The total transport contained within the coastal front is $T=T_{i}+T_{b}+T_{s}$. Both cases yield the same transport expression:

$$
T=\frac{g_{p}^{\prime} h^{2}}{2 f}\left[1-\frac{W}{W_{p}}+\frac{1}{3}\left(\frac{W}{W_{p}}\right)^{2}\right]=\gamma_{0} \frac{g_{p}^{\prime} h^{2}}{2 f},
$$

where $\gamma_{0}$ is a geometric or shape parameter dependent on the ratio of the front width $W$ to the plume total width $W_{p}=L+R$. There are two limiting cases. The most obvious is that of a narrow plume front, when (13) simplifies to $T \sim g_{p}^{\prime} h^{2} / 2 f$ as $W / W_{p} \rightarrow 0$. This is recognized as the transport of a two-layered ocean front (Garvine 1999; Fong and Geyer 2002; Lentz and Helfrich 2002). For very wide fronts where $W / W_{p} \rightarrow 1$, the transport becomes $T \sim g_{p}^{\prime} h^{2} / 6 f$. Similar analyses can be performed to compare $L$ and $R$ by rearranging the shape parameter as

$$
\begin{aligned}
\gamma_{0} & =1-\frac{n}{(L / R+1)}+\frac{n^{2}}{3(L / R+1)^{2}} \\
& =1-\frac{n}{(\beta / \alpha+1)}+\frac{n^{2}}{3(\beta / \alpha+1)^{2}},
\end{aligned}
$$

where $n=W / R$ and $\beta / \alpha$ is the ratio of the isopycnal to the shelf slope. Assuming $n$ is finite, for steep density 

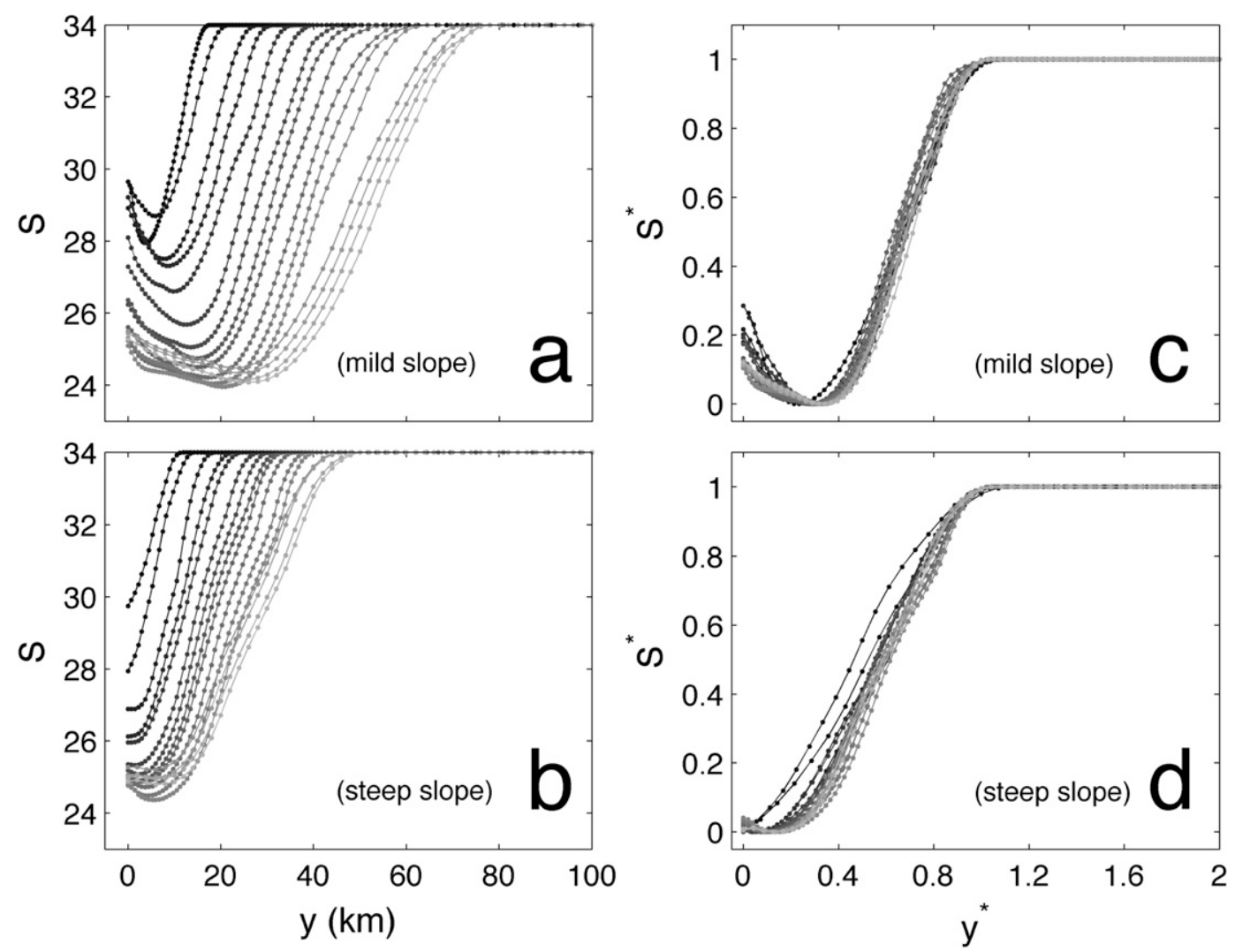

FIG. 8. Cross-shelf surface salinity as a function of river discharge for the (a) mild and (b) steep shelf slopes. Sections shown are located (10-20) $R_{d}$ from the estuary mouth. (c),(d) The cross-shelf distance $y$ is scaled by the plume width $y^{*}=y / W_{p}$ and the salinity $s$ by $s^{*}=\left(s-s_{p}\right) /\left(s-s_{a}\right)$, where $s_{p}$ is the minimum salinity within the plume and $s_{a}$ is the ambient water salinity. Lines indicate the river discharges, which vary from $Q_{r}=1000 \mathrm{~m}^{3} \mathrm{~s}^{-1}$ (dark gray) to $Q_{r}=100000 \mathrm{~m}^{3} \mathrm{~s}^{-1}$ (light gray).

fronts over mild continental slopes, $\beta \gg \alpha(L \gg R)(13)$ simplifies to $T \sim g_{p}^{\prime} h^{2} / 2 f$, as previously found for bottomtrapped fronts (Yankovsky and Chapman 1997). In a similar way, when $n \sim 1$ and surface-advected plumes are found over steep shelf slopes $\alpha \gg \beta(R \gg L)$, we obtain $T \sim g_{p}^{\prime} h^{2} / 6 f$, as previously found for stratified plumes against a coastal wall (Avicola and Huq 2003a).

The model also links the transport to an expression for the plume speed of propagation. Following Lentz and Helfrich (2002), we assume that the plume nose propagation velocity is given by $c_{p}=T / A_{p}$, where $A_{p} \sim h(L+R) / 2$ is the total plume cross-sectional area. This yield the expression

$$
c_{p}=\gamma_{0} \frac{g_{p}^{\prime} h}{f(L+R)}=\gamma_{0} \frac{g_{p}^{\prime} \beta}{f(\beta / \alpha+1)} .
$$

Note that as $R$ scales with the internal deformation radius $R \sim R_{d}=c_{w} / f$, we can rewrite $c_{p}=\gamma_{0} c_{w} /\left[\left(c_{w} / c_{\alpha}\right)+1\right]$, where $c_{w}=\sqrt{g_{p}^{\prime} h}$ and $c_{\alpha}=g_{p}^{\prime} \alpha / f$. This differs from the
Lentz and Helfrich (2002) expression only by the parameter $\gamma_{0}$, which varies from $\gamma_{0} \sim 1 / 3$ for wide to $\gamma_{0} \sim 1$ for narrow fronts. For the limiting case of steep fronts over mild shelf slopes, $L \gg R$, the plume propagation speed reduces to $c_{p} \sim \gamma_{0} c_{\alpha}$. This is recognized as the "shelf slope controlled" limit. On the other hand, as $R \gg L$, the "wall controlled" limit, $c_{p} \sim \gamma_{0} c_{w}$, is achieved (Lentz and Helfrich 2002).

\section{b. Plume transport and the river outflow}

The frontal model also connects the plume transport to the river upstream conditions. This is established by calculating the buoyancy anomaly flux. For the geometry shown in Figs. 9a and 9b,

$$
\begin{aligned}
T_{\rho}= & \iint_{A_{s}}(\delta \rho) u_{s} d a+\iint_{A_{\mathrm{b} 1}}(\delta \rho) u_{b} d a+\iint_{A_{\mathrm{b} 2}}(\delta \rho) u_{b} d a \\
& +\iint_{A_{i}}\left(\Delta \rho_{p}\right) u_{i}^{b} d a
\end{aligned}
$$



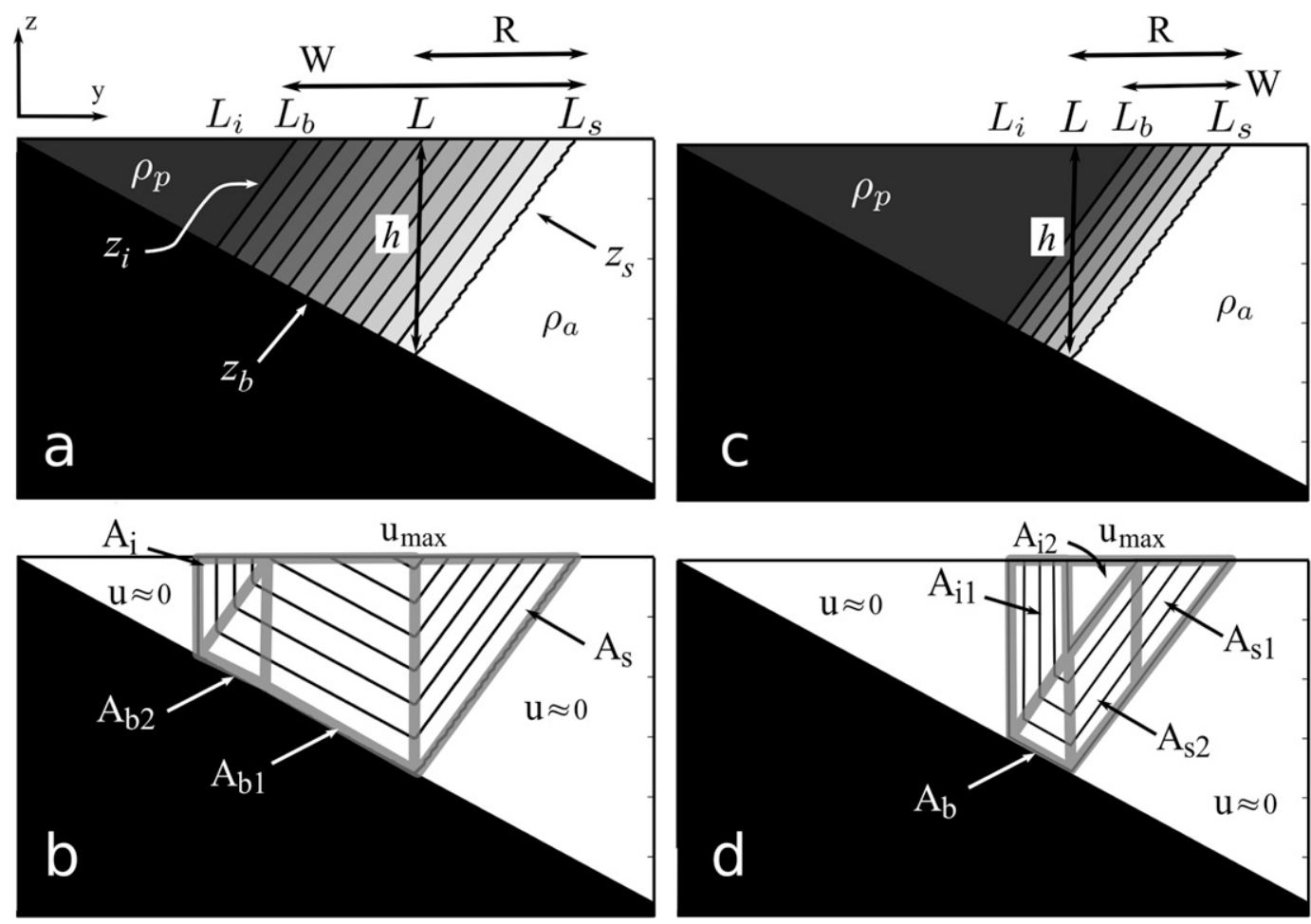

FIG. 9. (top) Plume frontal model density geometry and (bottom) along-shelf velocity field for the cases of (a),(b) a wide $R \leq W \leq W_{p}$ and (c),(d) a narrow $0 \leq W \leq R$ front. A linear front of width $W$ separates ambient shelf waters of density $\rho_{a}$ from inner shelf waters of density $\rho_{p}$. The plume maximum depth is $h$, which intersects the bottom at $y=L$. From $L$ the plume extends the distance $R$ along the surface offshore. The plume width is $W_{p}=L+R$. The shelf slope is $\alpha=h / L$, while the plume isopycnal slope is $\beta=h / R$. Plume regions cited in the text are indicated.

For the narrow-front case, shown in Fig. 9c and 9d,

$$
\begin{aligned}
T_{\rho}= & \iint_{A_{s 1}}(\delta \rho) u_{s} d a+\iint_{A_{s 2}}(\delta \rho) u_{s} d a+\iint_{A_{b}}(\delta \rho) u_{b} d a \\
& +\iint_{A_{\mathrm{i} 1}}\left(\Delta \rho_{p}\right) u_{i}^{b} d a+\iint_{A_{\mathrm{i} 2}}\left(\Delta \rho_{p}\right) u_{i}^{s} d a
\end{aligned}
$$

where $\delta \rho=\rho_{a}-\rho(y, z)$ is the buoyancy anomaly and the velocity expressions are given by (7)-(10). This results in an analytical expression of the following general form:

$$
T_{\rho}=\frac{1}{\gamma_{1}}\left(T \Delta \rho_{p}\right)
$$

where $\gamma_{1}=\gamma_{1}(L, R, W)$ is a shape parameter dependent of the plume geometry. The limiting cases for $\gamma_{1}$ are described further below. Ideally, the buoyancy flux should be conserved between the river and the coastal current. However, as part of this transport is sometimes diverted to the bulge growth, we introduce $\gamma_{2}$ to account for the fraction of the inlet buoyancy anomaly that is actually delivered downshelf (i.e., $T_{\rho}=\gamma_{2} \Delta \rho_{r} Q_{r}$ ). Finally, to account for the entrainment between the estuarine and shelf waters, we introduce $\gamma_{3}=\Delta \rho_{r} / \Delta \rho_{p}$. With these parameters the transport equation simplifies to

$$
T=\gamma Q_{r},
$$

where $\gamma=\gamma_{1} \gamma_{2} \gamma_{3}$.

This last equation establishes a practical relation between the plume transport and the river upstream that accounts indirectly for the mixing occurring within the estuary. This connection depends on priori knowledge of the plume structure (density $\rho_{p}$ and geometry), as well as the characteristics of the shelf (slope $\alpha$ and density $\rho_{a}$ ).

There are interesting limiting cases for $\gamma_{1}$. For simplification, we assume a situation where $\gamma_{2} \sim 1$ or where the freshwater is dominantly advected downshelf. The first case occurs when the frontal region narrows $(W \rightarrow 0)$, approximating the configuration of a Margules front. For this case $\gamma_{1} \sim 1$ and the plume transport reduces to $T \sim$ $Q_{r}\left(g_{r}^{\prime} / g_{p}^{\prime}\right)$; an expression previously used in Whitney and Garvine (2005). 
As the front widens $\left(W \rightarrow W_{p}\right), \gamma_{1}$ reduces to $\gamma_{1}=$ $4(L+R) /(L+2 R)$ or, in terms of the shelf and density slopes, $\gamma_{1}=4(\beta / \alpha+1) /(\beta / \alpha+2)$. As the shelf slope becomes steep $(\beta / \alpha \rightarrow 0), \gamma_{1} \sim 2$, in agreement with the relation $T \sim 2 Q_{r}\left(g_{r}^{\prime} / g_{p}^{\prime}\right)$ found by Avicola and Huq (2003a) for plumes against a coastal wall. The other limit should occur for a steep and wide density front, where $\gamma_{1}$ $\sim 4$. The general solution of $T_{p}$ and $\gamma_{1}$ from (15) and (16) involves a long polynomial, which is discussed in the appendix.

\section{c. Comparison with numerical simulations}

For the frontal model evaluation we use the inlet discharge $Q_{r}$ and density $\rho_{r}$, but the plume geometry must be established. Characteristics of the plume are obtained from cross sections between (10-20) $R_{d}$ downshelf of the estuary mouth in a region far from the bulge where the coastal current is well established. At these positions, the reduced gravity $g_{p}^{\prime}$ was computed from the minimum salinity of inner shelf waters. To reduce subjectivity, we defined the front as the region where the salinity local gradient is a fraction of the maximum gradient found across a region [e.g., $\left.\partial s / \partial y \leq(1 / k)(\partial s / \partial y)_{\max }\right]$. Fedorov (1986) suggests $k=10$, but for this analysis we employed $k=4$, as it best represented the cases studied. Offshore, this yields a boundary nearly coincident to the $s \sim 33.5$ isohaline. This establishes the plume surface and bottom boundaries for the coastal current sections. The parameters $h, L, W$, and $R$ obtained from this method are shown in Tables 2 and 3.

Figure 10 shows that the plume front width $W$ scales well with the plume total width $W_{p}=L+R$. Specifically, the plume geometry varies as $W \sim(3 / 4) W_{p}$, for the steep shelf slope, and approximately as $W \sim(3 / 5) W_{p}$, for the mild slope case. This simplifies (13) to $T \sim g_{p}^{\prime} h^{2} / 4 f$ for the mild slope shelf and $T \sim g_{p}^{\prime} h^{2} / 5 f$ for the steeper shelf case.

For the use of the expression $T=\gamma Q_{r}$, we must evaluate $\gamma_{1}, \gamma_{2}$, and $\gamma_{3}$. The $\gamma_{1}$ can be obtained from the integrals (15) and (16) (see the appendix). For the mild shelf slope, we find $\bar{\gamma}_{1} \sim 1.92$ on average and for the steeper shelf case this parameter yields $\bar{\gamma}_{1} \sim 1.83$. The fraction of buoyancy transport carried downshelf is computed as $\gamma_{2}=T_{p}\left(\Delta \rho_{r} Q_{r}\right)^{-1}$, with $T_{\rho}=\iint u\left(\rho_{a}-\rho\right) d a$. Finally, $\gamma_{3}=g_{r}^{\prime} / g_{p}^{\prime}$ is simply computed from the density observations. All parameters are listed in Tables 2 and 3.

The observed plume volume transport $T_{\text {obs }}$ is computed for each section and then plotted in Figs. 11a and 12a as scaled transport $\left(T_{\text {obs }} / Q_{r}\right)$. As seen, these plumes carry more than twice the river outflow. The estimated transport $T=\gamma Q_{r}$ is plotted as a black line in the same figures, with thin lines representing a variation on $g_{p}^{\prime}$ of \pm 0.005 . Note that the magnitude of the observed and estimated transports agrees within a small percentage of the error $(\sim 15 \%)$ (Tables 2 and 3 ). The results are also within the theoretical limits of transport discussed earlier. The latter are shown as dashed lines in the same graphs.

Using these transports, we can also infer the acrossshelf geometry of the coastal current. The plume depth and its Rossby radius of deformation are expressed as

$$
h=\left(\frac{2 T f}{\gamma_{0} g_{p}^{\prime}}\right)^{1 / 2} \quad \text { and } \quad R_{d}=\frac{\left(2 g_{p}^{\prime} T / \gamma_{0}\right)^{1 / 4}}{f^{3 / 4}}
$$

These are also compared against the model observations. The observed plume depth is shown as bullets and the depth estimation with a thick black line (Figs. 11b and $12 \mathrm{~b}$ ). It is found that plume depths vary from $5 \mathrm{~m}$ for smaller outflows to $35 \mathrm{~m}$ for very large outflows. The surface expansion of the plume $R$ also scales with the Rossby radius of deformation: $R \sim 1.5 R_{d}$ for a mild shelf and $R \sim 1.7 R_{d}$ for the steep case (Figs. $11 \mathrm{c}$ and $12 \mathrm{c}$ ). From these scales the plume cross-sectional area can be obtained from $A_{p} \sim(h / 2)(h / \alpha+R)$ (Figs. 11d and 12d). This shows a nearly linear relation of the plume sectional area to its outflow. The estimates of transport and plume area also give the plume propagation speed, $c_{p}=$ $T / A_{p}$. This result agrees with the observations of the nose velocity within $\sim 30 \%$ on average (Tables 2 and 3 ). The mild shelf plumes are classified as intermediate to bottom advected since $A_{n} / A_{s} \gtrsim 1$, and the steep shelf plumes as intermediate to surface advected, as generally $A_{n} / A_{s} \lesssim 1$ (Tables 2 and 3 ).

\section{d. Transport variability and the plume circulation}

The variability of the transport and the surface circulation within the plume is explored in this section. We adopt a streamwise coordinate system that follows the estuary outflow and the coastal current along the axis of nearly maximum surface speed, as shown in Fig. 13a. The downstream transport is computed from vertical cross sections taken along this downstream axis, shown as straight white lines in Fig. 13a. The observed transport is scaled by the river discharge $T_{\mathrm{obs}} / Q_{r}$ and plotted as a function of distance downshelf in Fig. 13b. The most vigorous entrainment occurs primarily within the estuary and secondarily near the turning region. In fact, for all of the simulations, nearly $65 \%$ of the plume transport $T$ is achieved before the exit of the estuary, as measured for sections sampled at a distance $r_{r}$ from the mouth (Tables 2 and 3). Beyond the estuary mouth, the 


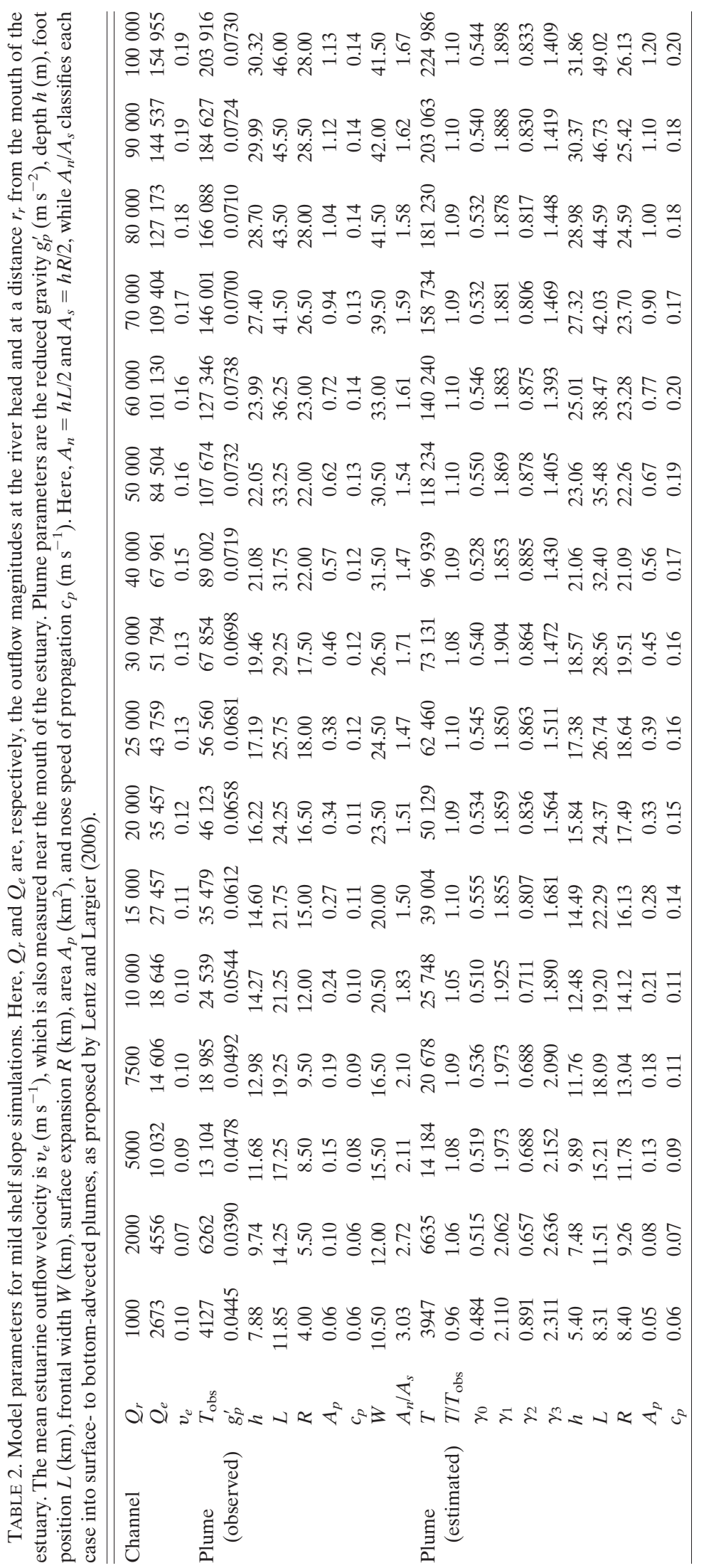




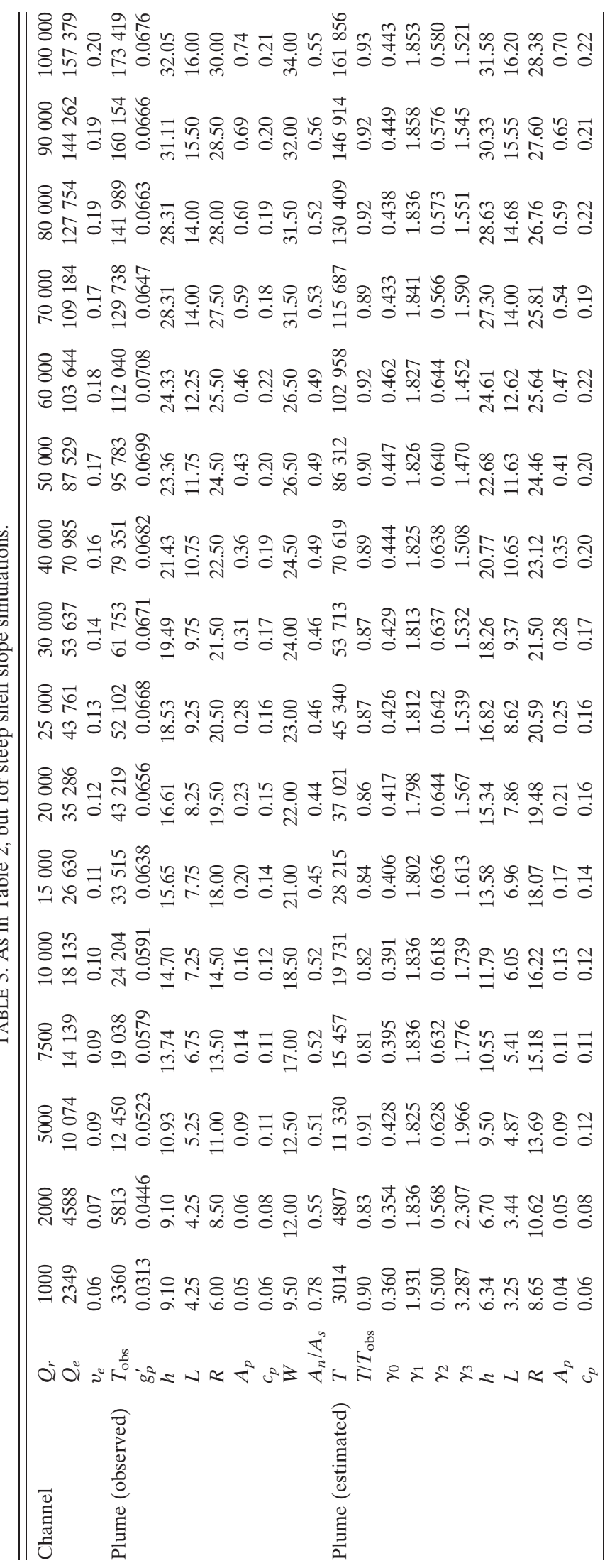




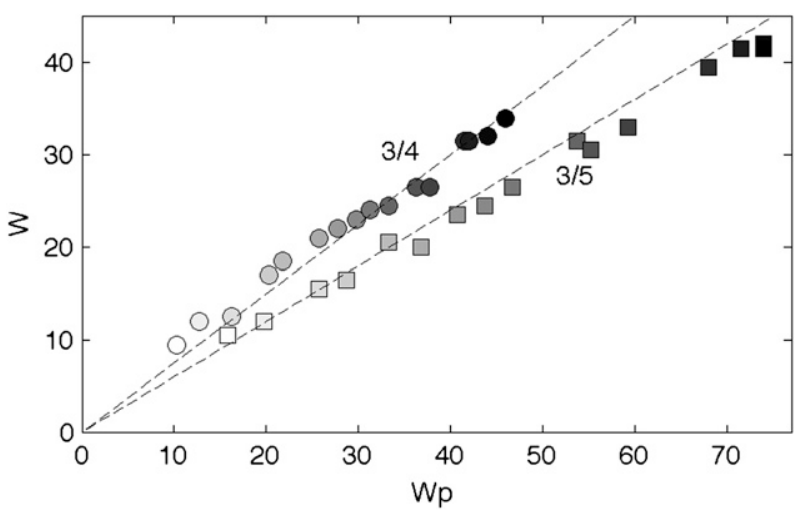

FIG. 10. Plume frontal width $W$ as function of the plume total width $W_{p}=L+R$. Bullets represent the steep shelf slope simulations and squares the mild slope simulations. The gray shades represent the discharges that vary from $Q_{r}=1000 \mathrm{~m}^{3} \mathrm{~s}^{-1}$ (white) to $Q_{r}=100000 \mathrm{~m}^{3} \mathrm{~s}^{-1}$ (black).

transport peaks around $x \sim 50 \mathrm{~km}$ in the vicinity of the bulge and diminishes slightly farther downstream. The plume transport is nearly twice the river outflow magnitude and remains remarkably constant in the coastal current region. Near the nose of the plume, the downshelf transport decays abruptly, filling the nearshore region behind the plume front.

This analysis also shows that the reduced gravity, which represents the strength of the coastal current, decays significantly from the estuary to the plume nose (Fig. 13c). Two sections, T1 and T2 of the coastal current, help to illustrate the changes in the structure of the plume (see insert graphs in Fig. 13a). Downstream at T1 the plume has a narrower frontal width, has steeper isopycnal slopes, and attains greater depths than the upstream section T2. These changes are reflected in how the coastal current depth $h$ and the form parameter $\gamma_{0} / 2$ vary downshelf. Figure $13 \mathrm{~d}$ shows that while the reduced gravity decays, the plume depth and the form parameter $\gamma_{0} / 2$ increase downstream. That is, as the plume becomes narrower and deeper, its transport can be maintained despite the decrease in $g_{p}^{\prime}$. The transport relation therefore changes from $T \sim g_{p}^{\prime} h^{2} / 4 f$ to almost $T \sim g_{p}^{\prime} h^{2} /$ $2 f$ as one approaches the nose region. Computing the transport from (13), we demonstrate that the estimate is valid well within the coastal current extension, as shown by the red line in Fig. 13b. The simplified model developed, however, does not account for the coastal current recirculation that occurs near the plume nose.
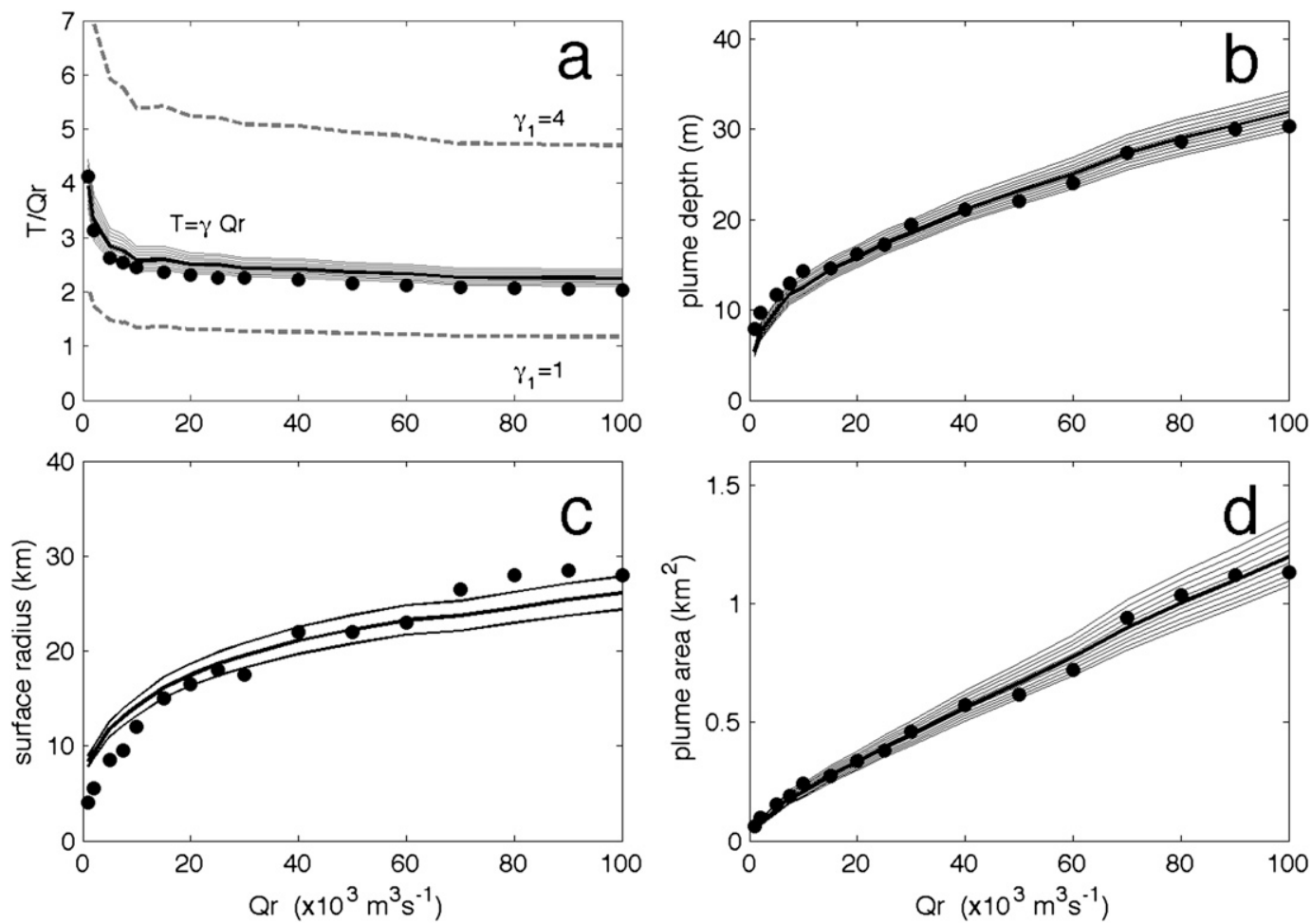

FIG. 11. Comparison of observed (bullets) and estimated (lines) coastal plume characteristics for the mild shelf slope simulations. (a) Scaled transport $T / Q_{r}$ as a function of river discharge $Q_{r}$. Black line corresponds to $T=\gamma Q_{r}$ and dash lines represent the $\gamma_{1}$ limits for narrow and wide fronts. (b) Coastal plume observed depth $h$, (c) plume offshore expansion as $R=(1.5 \pm 0.1) R_{d}$, and (d) plume cross-sectional area $A_{p}$. The thin gray lines in all graphs correspond to a variation on $g_{p}^{\prime}$ of \pm 0.005 with 0.001 increments. 

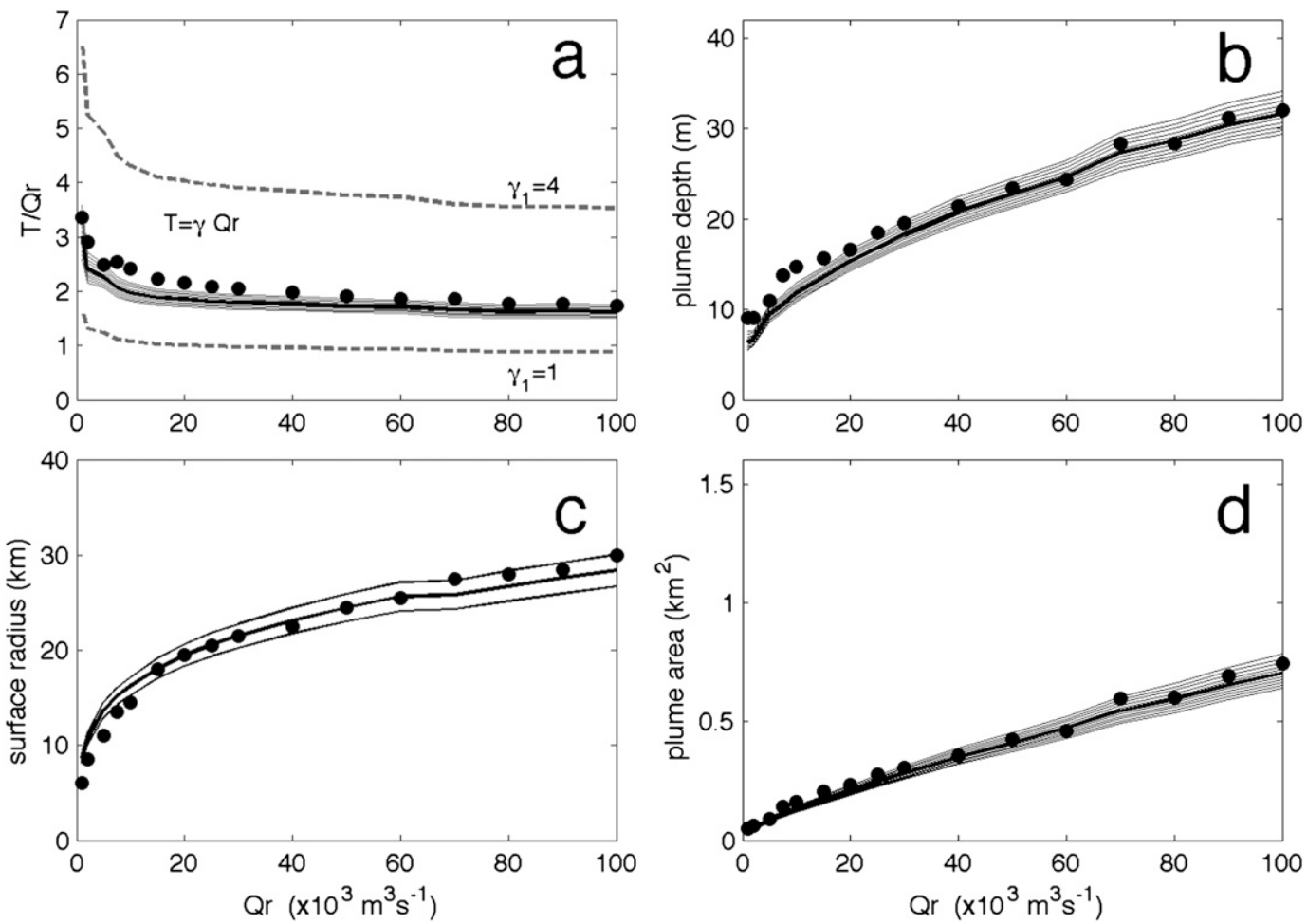

FIG. 12. As in Fig. 11, but for the steep shelf slope simulations and plume offshore expansion as $R=(1.7 \pm 0.1) R_{d}$.

Figure 13a also shows four different regimes of circulation from the surface velocity profiles that follow the coastal current system. The first occurs over the estuary domain, where horizontally sheared currents form two asymmetric jets, which is consistent with a frictionally adjusted flow (Valle-Levinson 2008). The transition of the estuary circulation to the coastal current occurs near the estuary mouth. There, we observe the estuary jets merging and a recirculation that forms a small bulge downstream. Farther downshelf a jet along the plume offshore front develops, while quiescent waters occupy the inner-shelf region. This jet narrows toward the nose of the plume, where the plume front turns anticyclonically toward the shore.

Details of the nose circulation from three plots taken 5 days apart by following the plume nose position are shown in Fig. 14. The horizontal velocity field here is relative to the nose velocity; that is, $u_{r}=u-c_{p}$. A flow field consistent with the circulation pattern described by Lentz and Helfrich's (2002) laboratory experiments develops. The circulation is characterized by a flow toward the nose near the outer region of the plume, which then turns onshore and upshelf near the coast. The flow closely follows the contours of the salinity, and because the offshore front bends toward the coast, the density field reverses temporarily for nearshore waters (Fig. 14 transects). The inner shelf region behind the nose show instabilities that decay over time as the plume propagates downshelf. This suggests that the nearshore meandering and generation of salty water filaments, as shown in Fig. 14, should be an important mechanism of mixing.

\section{Summary and conclusions}

Here, we have investigated the buoyant outflow delivery to a generic estuary and continental shelf domain through simulations with a primitive equation numerical model. Simulations were conducted for two shelf slopes and low Rossby number discharges. Plumes formed small bulges, displayed weak upshelf intrusions, and propagated downshelf transporting more volume than the specified river discharges. We found that significant entrainment occurred within the estuary and that the transport remains nearly constant along the coastal current.

A simple model for the plume front was developed. Its primary parameters are the river reduced gravity $g_{r}^{\prime}$ and discharge $Q_{r}$, the shelf slope $\alpha$, the plume frontal width $W$, isopycnal slope $\beta$, maximum depth $h$, and reduced gravity $g_{p}^{\prime}$. This model yielded two useful formulas. The first, $T=\gamma_{0}\left(g_{p}^{\prime} h^{2} / 2 f\right)$, linked the transport to the plume reduced gravity $g_{p}^{\prime}$; its depth $h$; and a parameter $\gamma_{0}$, which is dependent on the ratio of the front and the plume widths. The second considered the freshwater 



FIG. 13. (a) Top view of surface current speed (color scale) and velocity profiles. White lines depict velocity profiles that follow the plume coordinate system. The plume boundaries are depicted by gray salinity contours. In the insert graphs, $\mathrm{T} 1$ and $\mathrm{T} 2$ are salinity transects with downshelf flow shown as black contours. (b)-(d) The variations in properties along the shelf, which were measured along the plume coordinate system. (b) Observed and estimated transports, (c) reduced gravity, and (d) plume depth and $\gamma_{0} / 2$.

flux conservation within the buoyancy outflow. This related the plume transport $T$ directly to the upstream river outflow $Q_{r}$ through $T=\gamma Q_{r}$. In this expression, $\gamma=\gamma_{1} \gamma_{2} \gamma_{3}$ was composed of a shape parameter $\gamma_{1}$; the fraction of freshwater delivered downshelf, $\gamma_{2}$; and the downstream entrainment and mixing of fresh and shelf waters, $\gamma_{3}=g_{r}^{\prime} / g_{p}^{\prime}$. As with all parameterizations, these coefficients simplify a multitude of physical phenomena. In particular, $\gamma_{3}$ accounts for a number of processes responsible for estuarine entrainment while $\gamma_{2}$ accounts for the possible storage of freshwater by the bulge. Among these parameters, $\gamma_{1}$ and $\gamma_{3}$ are readily computed from bathymetric and hydrographic observations.

The estimation of $\gamma_{2}$ requires more detailed observations of the bulge circulation or some inference from the characteristics of the estuarine discharge. Numerical experiments provide some guidance on the choice of $\gamma_{2}$. The Fong and Geyer (2002) simulations suggest this parameter should be inversely proportional to the Rossby number, with $\gamma_{2}$ changing from 0.73 to 0.65 and 0.4 as the Rossby number increases, respectively, from 0.01 to 0.1 and 1 (see their Table 2 and Fig. 7). This is in agreement with observations of the Hudson plume, which demonstrate $\gamma_{2} \sim(0.4-0.5)$ for intermediate Rossby number outflows (Chant et al. 2008). However, depending on the estuary configuration, more freshwater might be expected to flow downshelf. Garvine (2001) demonstrated that the downshelf delivery of freshwaters will increase for estuaries with reduced inlet angles with the coastline, eventually achieving $\gamma_{2} \sim 1$ for $30^{\circ}$ angles, such as for the Delaware Bay. 

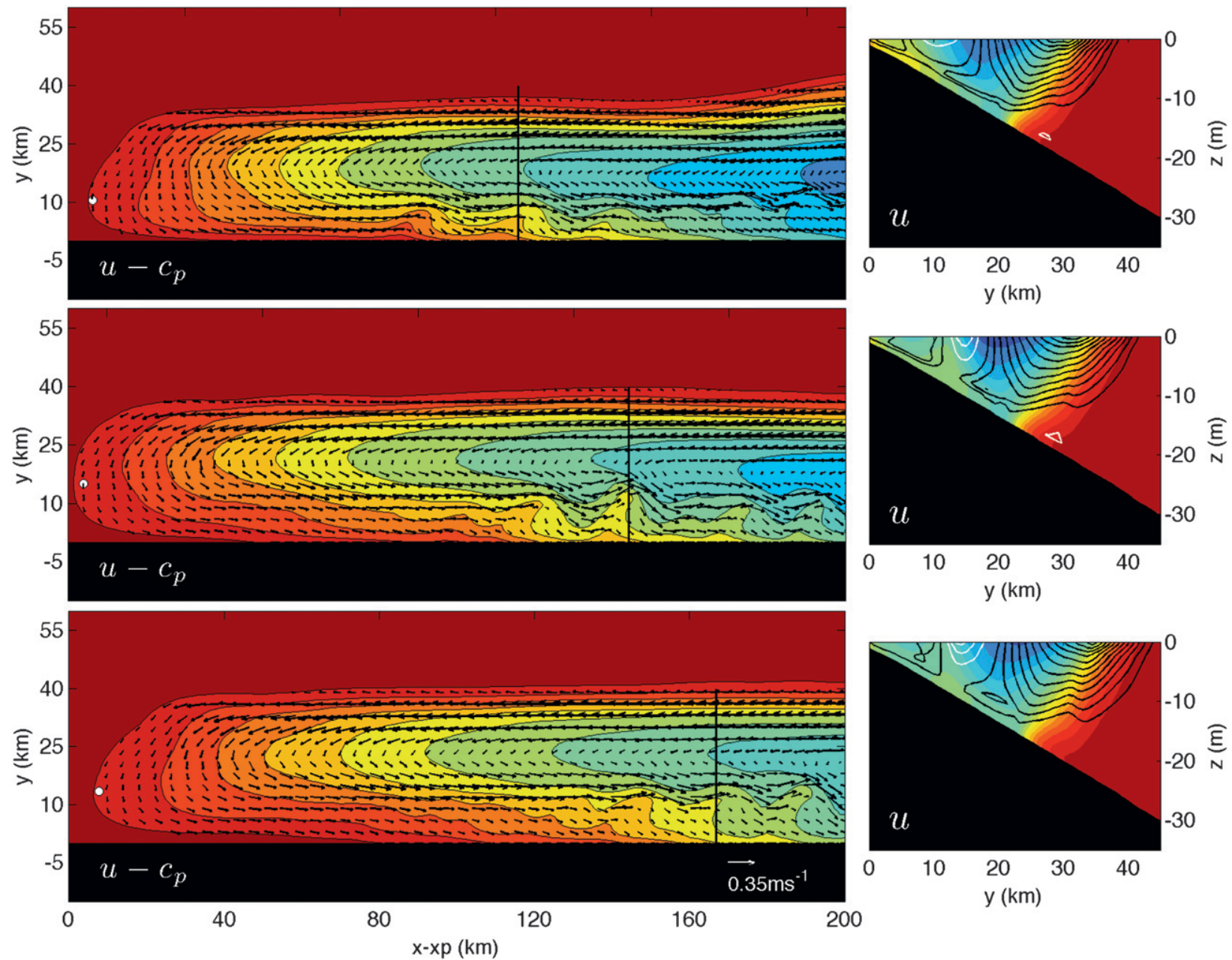

FIG. 14. (left) Flow field in a reference frame moving with the plume nose speed $c_{p}$. Velocity vectors for the plume field are overlaid on salinity contours. (right) Salinity vertical sections with along-shelf velocity. Here we plot velocity relative to a fixed frame of reference. Black (white) contours indicate downshelf (upshelf) flow, with $0.05 \mathrm{~m} \mathrm{~s}^{-1}$ increments. The fields are shown at 5-day intervals.

Both transport expressions reduce to known theoretical limits. The most generic situation is sketched in Fig. $15 \mathrm{a}$, which depicts a density front of width $W$ extending to a depth $h$ over a sloping shelf. By varying the width of the plume and the slopes of the shelf and the density field, we obtain the limiting cases. The first is obtained as the front narrows, approaching the configuration of a Margules front. The transport relation becomes $T \sim$ $g_{p}^{\prime} h^{2} / 2 f$, in agreement with expressions obtained for a plume against a wall (Fong and Geyer 2002) (Fig. 15c) or obtained for a narrow density front over a mild shelf slope (Yankovsky and Chapman 1997) (Fig. 15d). Further, assuming that the majority of the freshwater is advected downshelf $\gamma_{2} \sim 1$, the plume transport is linked to the river discharge simply by $T \sim Q_{r}\left(g_{r}^{\prime} / g_{p}^{\prime}\right)$, as shown in Whitney and Garvine (2005).

The second limit is obtained when the frontal width becomes comparable to the plume width over the shelf
(Fig. 15e); the transport relation becomes $T \sim g_{p}^{\prime} h^{2} / 6 f$. For this specific case, $\gamma_{1}$ depends on the shelf and isopycnal slopes. For a steep slope, $\gamma_{1} \sim 2$ and $T=2 Q_{r}\left(g_{r}^{\prime}\right)$ $g_{p}^{\prime}$ ), as shown by Avicola and Huq (2003a) (Fig. 15f). For a mild slope, $\gamma_{1} \sim 4$ (Fig. 15g). Observations of the Rio de la Plata and Delaware plumes indicate they should be classified between Figs. 15a and 15f. Although limit cases were not tested against the transport expressions, laboratory (Fig. 8 in Avicola and Huq 2002) numerical results (e.g., Fig. 3 in Fong and Geyer 2002 and Fig. 6 in Yankovsky and Chapman 1997) suggest their velocity and density fields are well reproduced by this simple analytic model. The case of a wide frontal region over a mild slope (Fig. 15g) needs to be studied further.

The numerical simulations revealed the presence of four distinct dynamical regions within the plume-estuary system: 1) the estuary domain, where vigorous mixing and entrainment occurs; 2) the turning region, where 


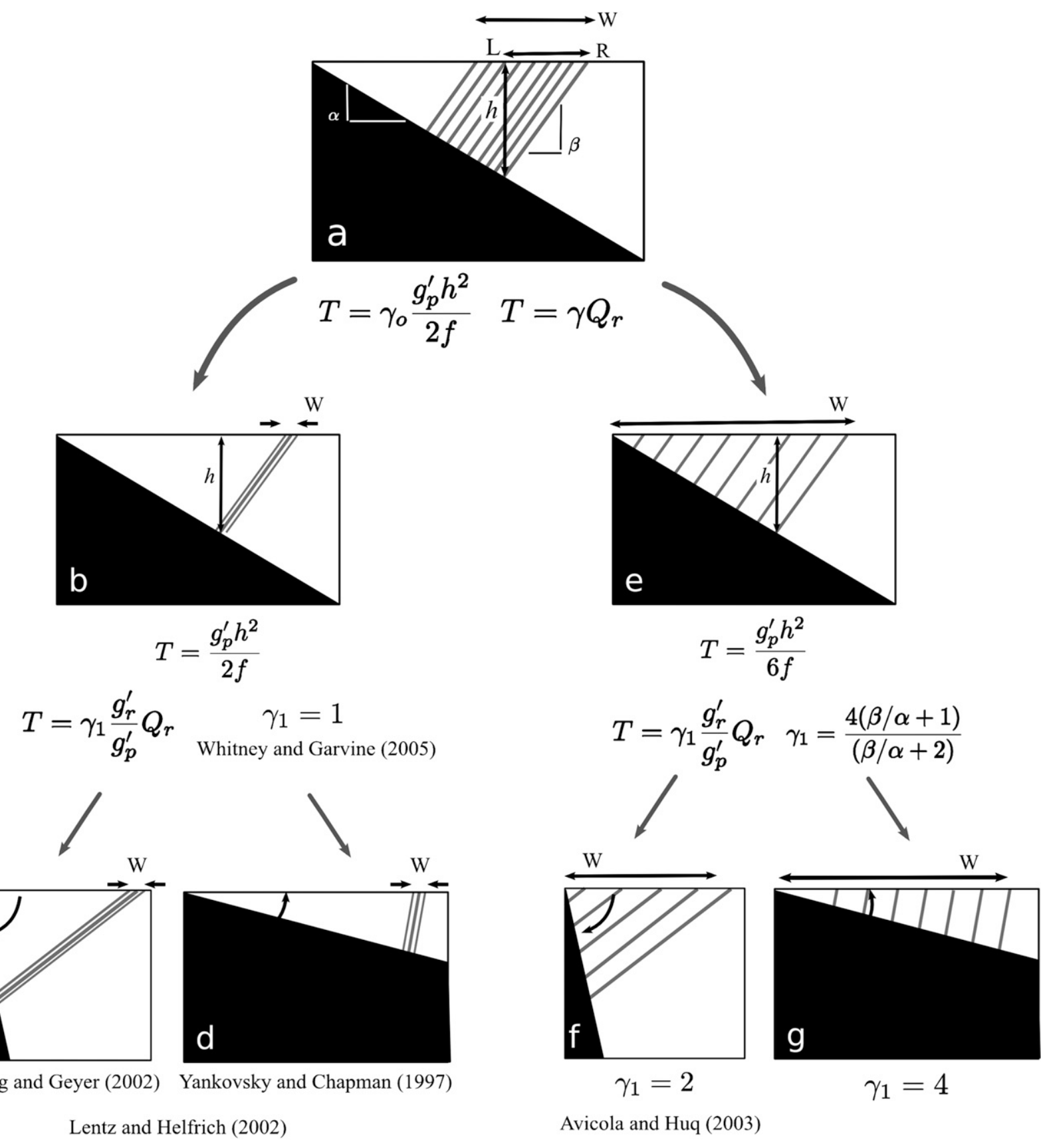

FIG. 15. Cartoon summarizing the transport relations for a buoyant coastal plume over a sloping bottom. By simplification, it is assumed that $\gamma_{2} \sim 1$, so that the freshwater is dominantly advected downshelf. (a) The generic configuration covered by the frontal model, (b) the limiting case for narrow coastal fronts, (c) a narrow front against a wall, and (d) a front over a mild shelf slope. (e) The other limits are found for a very wide frontal region, over a (f) steep and (g) mild shelf slope. Here, $\alpha=h / L$ and $\beta=h / R$ represent the shelf and isopycnal slopes.

a small bulge forms and the estuarine circulation transitions to the shelf regime; 3) the coastal current, characterized by nearly constant transport and an offshore jet that narrows downshelf and 4) the plume nose, where the coastal current veers toward the coast mixing with nearshore salty waters.
Although the model provides a dynamical rationale for estimating the transport carried out by a coastal plume, in many situations these assumptions represent simplifications of natural systems, as the plumes are constantly responding to the variability of environmental forcing mechanisms. The influence of these processes, 
however, could appear implicitly through the parameters considered by the model. For example, tidal forcing might lead to enhanced estuarine entrainment and a deeper, wider plume front with a weaker density contrast to the ambient ocean (Garvine 1999). Fluctuations of the estuarine outflow at tidal frequency should cause minor effects on the bulge structure whereas subinertial fluctuations $[\sim(5-10)$ days $]$ might alter substantially the transport due to the formation of downshelf propagating bulges (Yankovsky et al. 2001). Weak and brief wind events would modify the shape of the plume (Lentz and Largier 2006). Downwelling winds could augment the downshelf transport, while strong upwelling events would stall or even reverse the buoyant flow, leading to the detachment and dispersal of the plume (Rennie et al. 1999; Fong and Geyer 2001). Equally important, the implicit assumption of steady estuary outflow might be inappropriate when meteorological events promote the storage or release of freshwater to the ocean (e.g., Sanders and Garvine 2001).

A next step would be to compare our model results to velocity and hydrographic observations of plumes under different discharge magnitudes, ambient currents, and winds. It would also be interesting to test this model for high Rossby number discharges and to extend its application to the case of distributed source outflows such as numerous small estuaries. Finally, it would be useful to derive indirect methods to estimate $\gamma_{2}$ from hydrographic or remote sensing observations of estuarine bulges.

Acknowledgments. FMP acknowledges the Brazilian CAPES Foundation (BEX 2242/03-6) and the University of Delaware Sea-Grant Program for their support. ADK acknowledges the support of the Mary. A. S. Lighthipe Endowment to the University of Delaware. The original manuscript was improved through the helpful comments of two anonymous reviewers.

\section{APPENDIX}

\section{Calculation of Buoyancy Anomaly Transport $T_{\rho}$}

The form parameter $\gamma_{1}$ can be directly evaluated from the expressions for the plume transport and for the buoyancy anomaly transport. The first is given by Eq. (13), while the latter is obtained from the integrals (15) and (16). The general solution for the buoyancy transports yields long expressions. These can be compactly written as

$$
T_{\rho}=\Delta \rho_{p} \frac{g_{p}^{\prime} h^{2}}{2 f}\left(\frac{\sum_{i=0}^{m} P_{i}}{D}\right),
$$

where for the wide fronts $(R \leq W \leq L+R), m=4$ and

$$
\begin{aligned}
& P_{0}=-R^{2}(L+R)^{3}, \\
& P_{1}=4 R(L+R)^{3} W, \\
& P_{2}=6(L+R)^{2}(L-R) W^{2}, \\
& P_{3}=-4(L+R)(2 L-R) W^{3}, \\
& P_{4}=(3 L-R) W^{4}, \text { and } \\
& D=12 L(L+R)^{2} W^{2} .
\end{aligned}
$$

For the case of a narrow front $(0 \leq W \leq R), m=2$ and

$$
\begin{aligned}
& P_{0}=12 R^{2}(L+R)^{2}, \\
& P_{1}=-12 R(L+R)(L+2 R) W, \\
& P_{2}=\left(15 L^{2}+31 L R+20 R^{2}\right) W^{2}, \text { and } \\
& D=12 R^{2}(L+R)^{2} .
\end{aligned}
$$

The form parameter $\gamma_{1}$ can be obtained by inserting (13) and (A1) into

$$
\gamma_{1}=\frac{\Delta \rho_{p} T}{T_{p}} .
$$

For the numerical simulations studied here, these transport expressions were greatly simplified by noting that the frontal width $W$ scaled well to the plume width $W_{p}=$ $L+R$. For the mild shelf slope, the frontal width was approximately $W \sim(3 / 5) W_{p}$, so that $T \sim g_{p}^{\prime} h^{2} / 4 f$ and $T_{\rho}=$ $\Delta \rho_{p}\left(g_{p}^{\prime} h^{2} / 2 f\right)\left\{\left[513 L^{2}+1122 L R-16 R^{2}\right] /[2700 L(L+\right.$ $R)]\}$. For the steep shelf, we found $W \sim(3 / 4) W_{p}$, so that the transport expressions were $T=g_{p}^{\prime} h^{2} / 5 f$ and $T_{\rho}=\Delta \rho_{p}\left(g_{p}^{\prime} h^{2} / 2 f\right)\left\{\left[243 L^{2}+498 L R-R^{2}\right] /[1728 L(L+\right.$ $R)]\}$.

\section{REFERENCES}

Austin, J. A., 2002: Estimating the mean ocean-bay exchange rate of the Chesapeake Bay. J. Geophys. Res., 107, 3192, doi:10.1029/2001JC001246.

Avicola, G., and P. Huq, 2002: Scaling analysis for the interaction between a buoyant coastal current and the continental shelf: Experiments and observations. J. Phys. Oceanogr., 32, 32333248.

_ and _ 2003a: The characteristics of the recirculating bulge region in coastal buoyant outflows. J. Mar. Res., 61, 435-463.

$\longrightarrow$, and $-2003 \mathrm{~b}$ : The role of outflow geometry in the formation of the recirculating bulge region in coastal buoyant outflows. J. Mar. Res., 61, 411-434.

Blanton, J. O., and L. P. Atkinson, 1983: Transport and fate of river discharge on the continental shelf of the southeastern United States. J. Geophys. Res., 88 (C8), 4730-4738. 
Blumberg, A. F., and G. L. Mellor, 1987: A description of a threedimensional coastal ocean circulation model. Three-Dimensional Coastal Ocean Models, N. S. Heaps, Ed., Amer. Geophys. Union, $1-16$.

Chant, R. J., S. M. Glenn, E. Hunter, J. Kohut, R. F. Chen, R. W. Houghton, J. Bosch, and O. Schofield, 2008: Bulge formation of a buoyant river outflow. J. Geophys. Res., 113, C01017, doi:10.1029/2007JC004100.

Chao, S.-Y., 1987: Wind-driven motion near inner shelf fronts. J. Geophys. Res., 92 (C4), 3849-3860.

Chapman, D. C., and S. J. Lentz, 1994: Trapping of a coastal density front by the bottom boundary layer. J. Phys. Oceanogr., 24, 1464-1479.

Fedorov, K. N., 1986: The Physical Nature and Structure of Oceanic Fronts. Lecture Notes on Coastal and Estuarine Studies, Springer, $333 \mathrm{pp}$.

Flather, R. A., 1976: A tidal model of the northwest European continental shelf. Mem. Soc. Rot. Sci. Liege, 6 (10), 141-164.

Fong, D. A., and W. R. Geyer, 2001: Response of a river plume during an upwelling favorable wind event. J. Geophys. Res., 106 (C1), 1067-1084.

$\longrightarrow$, and - 2002: The alongshore transport of freshwater in a surface-trapped river plume. J. Phys. Oceanogr., 32, 957-972.

Gan, J., and J. S. Allen, 2002: A modeling study of shelf circulation off northern California in the region of the Coastal Ocean Dynamics Experiment: Response to relaxation of upwelling winds. J. Geophys. Res., 107, 3123, doi:10.1029/2000JC000768.

Garvine, R. W., 1995: A dynamical system for classifying buoyant coastal discharges. Cont. Shelf Res., 13, 1585-1596.

1999: Penetration of buoyant coastal discharge onto the continental shelf: A numerical model experiment. J. Phys. Oceanogr., 29, 1892-1909.

- 2001: The impact of model configuration in studies of buoyant coastal discharge. J. Mar. Res., 59, 193-225.

Guerrero, R. A., E. M. Acha, M. B. Framiañan, and C. A. Lasta, 1997: Physical oceanography of the Río de la Plata estuary, Argentina. Cont. Shelf Res., 17, 727-742.

Henrichs, S., N. Bond, R. Garvine, G. Kineke, and S. Lohrenz, 2000: Coastal Ocean Processes (CoOP): Transport and transformation processes over continental shelves with substantial freshwater inflows. University of Maryland Center for Enviroment Science Tech. Rep. TS-237-00, 131 pp.

Hill, A. E., 1998: Buoyancy effects in coastal and shelf seas. The Sea, A. R. Robinson and K. H. Brink, Eds., The Global Coastal Ocean, Vol. 10, John Wiley and Sons, 21-62.

Horner-Devine, A. R., D. A. Fong, S. G. Monismith, and T. Maxworthy, 2006: Laboratory experiments simulating a coastal river inflow. J. Fluid Mech., 555, 203-232, doi:10.1017/S0022112006008937.

Klinck, J. M., 1996: Circulation near submarine canyons: A modeling study. J. Geophys. Res., 101, 1211-1223.

Lentz, S. J., and K. R. Helfrich, 2002: Buoyant gravity currents along a sloping bottom in a rotating fluid. J. Fluid Mech., 464, 251-278, doi:10.1017/S0022112002008868.

, and J. Largier, 2006: The influence of wind forcing on the Chesapeake Bay buoyant coastal current. J. Phys. Oceanogr., 36, 1305-1316.
Martinsen, E. A., and H. Engedahl, 1987: Implementation and testing of a lateral boundary scheme as an open boundary condition in a barotropic ocean model. Coastal Eng., 11, 603-627.

Mellor, G. L., 2004: Users guide for a three-dimensional, primitive equation, numerical ocean model. Program in Atmospheric and Ocean Sciences, Princeton University, 53 pp. [Available online at http://www.aos.princeton.edu/WWWPUBLIC/htdocs.pom/.] , and T. Yamada, 1982: Development of a turbulence closure model for geophysical fluid problems. Rev. Geophys. Space Phys., 20, 851-875.

Moline, M. A., and Coauthors, 2008: Biological responses in dynamic buoyant river plume. Oceanography, 21 (4), 71-88.

Möller, O. O., A. R. Piola, and A. C. Freitas, 2008: The effects of river discharge and seasonal winds on the shelf off southeastern South America. Cont. Shelf Res., 28, 1607-1624.

Münchow, A., and R. W. Garvine, 1993a: Buoyancy and wind forcing of a coastal current. J. Mar. Res., 51, 293-322.

_, and _ 1993b: Dynamical properties of buoyancy-driven coastal current. J. Geophys. Res., 98 (C11), $20063-20077$.

Orlanski, I., 1976: A simple boundary condition for unbounded hyperbolic flows. J. Comput. Phys., 21, 251-269.

Piola, A. R., O. O. Möller, R. A. Guerrero, and E. J. D. Campos, 2008: Variability of the Subtropical Shelf Front off eastern South America: Winter 2003 and summer 2004. Cont. Shelf Res., 28, 1639-1648, doi:10.1016/j.csr.2008.03.013.

Rennie, S. E., J. L. Largier, and S. J. Lentz, 1999: Observations of a pulsed buoyancy current downstream of Chesapeake Bay. J. Geophys. Res., 104 (C8), 18 227-18 240.

Royer, T. C., 1982: Coastal fresh water discharge in the northeast Pacific. J. Geophys. Res., 87 (C3), 2017-2021.

Sanders, T. M., and R. W. Garvine, 2001: Fresh water delivery to the continental shelf and subsequent mixing: An observational study. J. Geophys. Res., 106 (C11), 27 087-27 101.

Simpson, J. H., 1997: Physical processes in the ROFI regime. J. Mar. Syst., 12, 3-15, doi:10.1016/S0924-7963(96)00085-1.

Smagorinsky, J., 1963: General circulation experiments with the primitive equations, 1 . The basic experiment. Mon. Wea. Rev., 91, 99-104.

Smolarkiewicz, P. K., and W. W. Grabowski, 1990: The multidimensional positive definite advection transport algorithm. J. Comput. Phys., 86, 355-375.

Valle-Levinson, A., 2008: Density-driven exchange flow in terms of the Kelvin and Ekman numbers. J. Geophys. Res., 113, C04001, doi:10.1029/2007JC004144.

Whitney, M. M., and R. W. Garvine, 2005: Wind influence on a coastal buoyant outflow. J. Geophys. Res., 110, C03014, doi:10.1029/2003JC002261.

Wong, K.-C., and A. Münchow, 1995: Buoyancy forced interaction between estuary and inner shelf: Observation. Cont. Shelf Res. 15, 59-88, doi:10.1016/0278-4343(94)P1813-Q.

Yankovsky, A. E., and D. C. Chapman, 1997: A simple theory for the fate of buoyant coastal discharges. J. Phys. Oceanogr., 27, 1386-1401.

— B. M. Hickey, and A. Münchow, 2001: Impact of variable inflow on the dynamics of a coastal buoyant plume. J. Geophys. Res., 106 (C9), 19 809-19 824. 
Copyright of Journal of Physical Oceanography is the property of American Meteorological Society and its content may not be copied or emailed to multiple sites or posted to a listserv without the copyright holder's express written permission. However, users may print, download, or email articles for individual use. 